\title{
Long-Term Care Insurance: Information Frictions and Selection*
}

\author{
M. Martin Boyer \\ HEC Montréal
}

\author{
Philip
TSE
eroux
}

Marie-Louise Leroux

ESG UQAM

\author{
Claude Fluet \\ Université Laval
}

December 2017; October 2019

\begin{abstract}
This paper conducts a stated-choice experiment where respondents are asked to rate various insurance products aimed to protect against financial risks associated with long-term care needs. Using exogenous variation in prices from the survey design and individual cost estimates, these stated-choice probabilities are used to predict market equilibrium for long-term care insurance. Our results are twofold. First, information frictions are pervasive. Second, measuring the welfare losses associated with frictions in a framework that also allows for selection, it is found that information frictions reduce equilibrium take-up and lead to large welfare losses while selection plays little role.
\end{abstract}

Keywords: Long-term care insurance, adverse selection, stated-preference, health, insurance.

\footnotetext{
${ }^{*}$ We acknowledge financial support from the Social Science and Humanities Research Council of Canada (4352016-1109), and from the French Agence Nationale de la Recherche under grant ANR-17-EURE-0010 (Investissements d'Avenir program). Philippe De Donder also thanks the financial support from "Chaire Marché des risques et création de valeurs, fondation du risque/Scor". We wish to thank Pierre-André Chiappori, Georges Dionne, Meghan Esson, Andreas Richter, and Christopher Tonetti for helpful comments and suggestions. We thank seminar participants at the Financing Longevity Conference at Stanford, KU Leuven, HEC Montréal, 2018 NETSPAR meetings, the 2017 American Risk and Insurance Meetings, and at the 2018 Munich Behavioral Insurance Conference for their comments and suggestions. We also thank Sébastien Box-Couillard and Francois Laliberté-Auger for excellent research assistance and David Boisclair for help with the design of the questionnaire.
} 


\section{Introduction}

Because of rapidly aging population, financing and providing long-term care (LTC hereafter) to older individuals is an important and growing problem in developed countries. ${ }^{1}$ In OECD countries, the population of 80 years old and more is expected to grow from $4 \%$ of the total population in 2010 to $10 \%$ by 2050 (OECD, 2011). Estimates of the probability that someone approaching retirement will use a nursing home at some point in his life ranges from $35 \%$ to $50 \%$ in the U.S. (Brown and Finkelstein, 2009; Hurd et al., 2017). Despite increasing demand, OECD countries are still spending relatively little on long-term care services, at least as a percentage of GDP. Private long-term expenditures as a share of GDP were similar in Canada and the United States at roughly $0.3 \%$ of GDP. ${ }^{2}$

To get a sense of the magnitude of private expenditures in Canada, out-of-pocket costs for a public nursing home is at most $\$ 24,000$ a year representing roughly a third of total cost to the government ${ }^{3}$ in the province of Québec (see Boyer et al. (2019a) for more on the out-of-pocket costs in the different Canadian provinces), compared to over 90,000 USD in the United States (Genworth, 2019). Given that, on average, individuals stay 5 years in these facilities, such longterm care expenses can represent a high burden for households with low savings. Moreover, public nursing homes only provide "minimum basic services" so that an individual who would like to receive "higher quality services" would have to resort to a private nursing home whose cost varies between $\$ 40,000$ and $\$ 60,000$ a year in Canada. ${ }^{4}$ Finally, the waiting time for accessing the public service is close to 10 months so that, while waiting for a bed in a Canadian nursing home, individuals need to find alternative (private) solutions. Hence, LTC risk is associated with potentially important financial risks for households despite subsidies from the government.

In order to cover for the risk that public care is not enough or is unavailable when additional

\footnotetext{
${ }^{1}$ Long term care is defined as the care for people needing daily living support over a prolonged period of time. Support can be provided with activities of daily living (such as bathing, dressing, eating, getting in and out of bed, toileting and continence) or instrumental activities of daily living (which include preparing meals, cleaning, doing the laundry, taking medication, getting to places beyond walking distance, shopping, managing money affairs, and using the telephone and nowadays the Internet). The loss of autonomy is most often associated with old age and should be clearly distinguished from illness, disability and handicap.

${ }^{2}$ Recent OECD Health statistics (2018) suggest that, in 2016, the 30 OECD countries spent, on average, $1.33 \%$ of GDP on long-term care services (with $1.10 \%$ of GDP coming from public sources and $0.23 \%$ coming from private sources). For the same year total expenditure on long-term care services in the United States represented $0.87 \%$ of GDP, with $0.24 \%$ of GDP coming from non-government sources. In Canada, total expenditures on long-term care services represented $1.48 \%$ of GDP, with private sources representing $0.31 \%$ of GDP.

${ }^{3}$ Unless otherwise specified, amounts are expressed in Canadian dollars throughout the paper.

${ }^{4}$ The two provinces in which we conducted our study, namely Québec and Ontario, provide dependents with means-tested reduction in fees. In addition, in the province of Québec, tax-credits for formal care are available.
} 
services are required, Canadians can buy a private LTC insurance policy that pays off when they are declared to have two ADL impairments or more (payments cannot be retroactive). Contrary to some other countries, bundling LTC insurance with some other financial products is quite limited.

Despite the high potential financial risk for individuals and households, very few choose to insure privately against such risks (Pestieau and Ponthiere, 2011). In Canada, the share of total LTC spending covered by private insurance was around $0.5 \%$ in 2010 while for OECD countries, it was less than 2\% (OECD, 2011). According to a Canadian Life and Health Insurers Association representative, the take-up rate in Québec for long-term care insurance policies was around $1.7 \%$ in $2015 .^{5}$ This situation is often coined the Long-Term Care Insurance Puzzle.

The objective of this paper is to explain low take-up rate of LTC insurance (LTCI hereafter), and to measure the welfare costs of (demand side) choice frictions and (supply side) asymmetric information. To do so, we partnered with Asking Canadians, a Canadian online panel survey organization to field a survey on LTCI, in the fall of 2016. We selected randomly 2000 panel members aged 50 to 70 in the two most populous provinces of Canada, Ontario and Québec. We then matched each respondent with a health microsimulation model capable of estimating personalized lifetime exposure to disability, nursing home and formal care (Boisclair et al., 2016). This allows to estimate the actual risks faced by households and potentially covered by insurers and to compare those with risk perceptions we elicit in the survey. We also survey respondents about their knowledge of LTC and institutional details and preferences for care which have been shown to be correlated with demand for LTCI (Brown et al., 2012). We then build a statedpreferences experiment to study demand for LTCI. ${ }^{6}$ The second part of our survey consists of an experiment where we presented each respondent with the prospect of purchasing a LTCI product. These scenarios differ in terms of the benefit paid in case of dependency, the premium paid and the provision of an embedded term life insurance contract if the respondent dies prior to age 85 . From survey responses and experimental variation in contract characteristics, we can infer the participants' demand for LTCI and investigate whether there is adverse or advantageous selection in this insurance market.

\footnotetext{
${ }^{5}$ In the U.S., only about 10.8 percent of those 60 years and older held such a policy in 2009 (Brown and Finkelstein, 2009). Put differently, in 2010, 10 million Americans were covered by some sort of long-term care insurance policy, compared to 385,000 Canadians (see clhia.uberflip.com/i/354914-clhia-report-on-long-term-care-policy/ 7?). Liu and Liu (2019) report that, as of 2014, there were 7.2 million private LTCI policies in force in the United States.

${ }^{6}$ See Louviere et al. (2000) on the merits and disadvantages of stated-choice experiments.
} 
We build on the methodology developed by Einav et al. (2010) and Handel et al. (2019). The former uses revealed preferences to estimate the demand and supply curves of employer-provided health insurance using individual-level data from a multinational firm. The combination of estimated demand and supply curves enables to evaluate the welfare losses associated with mispricing due to asymmetric information (whether it is adverse or advantageous selection). We extend this approach to stated-preference data using experimental variation in prices. Handel et al. (2019) estimates the extent to which the presence of information frictions in the health insurance market would lead to inefficiencies and how policy interventions for correcting these frictions may effectively be welfare increasing or decreasing. ${ }^{7}$ Following a similar approach, we estimate the welfare impact of those information frictions in the Canadian LTCI market according to our survey.

Our results confirm the existence of under-insurance for LTC. Focusing on the baseline contract offering a $\$ 2000$ LTC monthly benefit without any life insurance, our model predicts that the proportion of agents optimally buying LTC should be around 30\% while the equilibrium take-up rate is only 20\%. Asymmetric information explains only a very tiny fraction of this gap (in the absence of asymmetric information, the equilibrium take-up rate would decrease by $0.4 \%$ ), and consequently generates a very small welfare cost. The largest part of the take-up gap is rather explained by information frictions regarding the general knowledge of LTCI products (awareness), and the knowledge of LTC costs and institutional context in general, with a much smaller role for misperceptions regarding survival and disability risks. We estimate the overall welfare cost of these information frictions at around $18 \%$ of the welfare obtained at the social optimum.

Few papers combine stated-preference and revealed preference data to study this market. Exceptions are Ameriks et al. (ming) and Ameriks et al. (2016). The latter study uses strategic survey questions along with balance sheet data from the Vanguard Research Initiative (VRI) to estimate preferences, within a well-defined life-cycle model, to explain the low demand for LTCI products. They find that $60 \%$ of the panel members would buy LTCI according to their model. This gap between actual and reported demand can be explained by a lack of interest on the demand side as well as poor insurance product features on the supply side. In our framework, we elicit directly preferences of respondents allowing us to compute the demand curve using experimental variation in prices. We also consider the supply and demand side

\footnotetext{
${ }^{7}$ See also Handel and Kolstadt (2015) and Spinnewijn (2017).
} 
jointly, allowing us to investigate selection and equilibrium in that market. Another related paper is Dardanoni and Li Donni (2016) who use a framework similar to ours but in a revealed preference context. Their approach rests on evaluating welfare losses from mixture type models using external estimates of the price elasticity of demand for LTCI. They estimate large welfare loss from unpriced heterogeneity and use large estimates of the price elasticity of demand (3.5 and -2). In our framework, we estimate this elasticity directly from the stated-preference experiment and find price elasticities (average around -0.65) consistent with Ameriks et al. (2016) who find demand price elasticity below one (in absolute value) for $80 \%$ of their sample.

Finally our paper can be related to the developing literature on behavioral insurance. ${ }^{8}$ This literature focuses on the importance of taking into account behavioral constraints (i.e., specific individual cognitive factors and limited rationality) when it comes to explaining individuals' insurance behavior. Insurance choices are quite different from other (risky) choices and, as such, are impacted differently by behavioral constraints. While some papers have already integrated these constraints into models of insurance for disasters (Friedl et al., 2014), for genetic testing (Hoy et al., 2014), for annuitization (Bommier and Grand, 2014), for health damages (Handel and Kolstadt, 2015) etc., to the best of our knowledge, our paper is the first empirical paper to study the impact of behavioral constraints on LTCI take-up and to quantify their welfare impacts.

The paper is organized as follows. Section 2 describes the survey and the questionnaire we use. Section 3 shows descriptive evidence from the survey. We develop an equilibrium model for LTCI products, which we apply to stated-preference data from our survey, in Section 4. Section 5 contains the results we obtain, while Section 6 concludes.

\section{Data}

We first describe the survey we have run, before moving to how we have computed the individuals' LTC risk from their survey answers.

\subsection{Survey}

Partnering with Asking Canadians, a Canadian online panel survey organization, we conducted a survey on LTCI in late autumn 2016. We randomly selected 2000 panel members aged 50 to

\footnotetext{
${ }^{8}$ For an overview of the issues related to behavioral insurance, see Richter et al. (2014).
} 
70 residing in the two largest and most populous provinces of Canada, Ontario and Québec. Participants were rewarded for their participation with loyalty rewards from major retailers. Despite those efforts, some groups remain slightly underrepresented, in particular low-educated and low-income groups. We stratified by age, gender, province and education groups (three levels) and used the Canadian Labor Force Survey of 2014 (the last year available) to re-weigh the data. The effect of weighing was minimal on our analysis. For example, the median household income we estimate in the survey is $\$ 65,000$ for the province of Québec, while the equivalent number from the Social Policy Simulation Database (SPSD) for 2016 is $\$ 69,000$. The 25th percentile of household income in the SPSD is $\$ 41,110$ for Québec while we estimate it to be $\$ 38,000$ in our survey. Hence, once reweighed, our survey appears representative of the population aged 50-70 in Québec and Ontario.

A copy of the questionnaire (in text format) is found in Appendix C. It has four major parts. ${ }^{9}$ The first three parts asked respondents about socioeconomic characteristics, reasons for having purchased (or not) LTCI, risk perceptions and, their preferences regarding the type of LTC they would prefer to receive. For some of these questions, we used a formulation taken from Brown et al. (2012). For questions where we expected a significant fraction of missing information, such as savings and income, we used unfolding brackets. We then used multiple imputation to impute missing values with information from the bracketing, conditional on basic socio-demographic co-variates (age, gender).

The fourth and last part of the survey consisted of a stated-preference experiment. Respondents were presented with the prospect of purchasing a LTCI product. These scenarios differ in the benefit paid under LTCI, the premium and a term life insurance if the respondent dies prior to age 85. The introductory text is reproduced below (the equivalent exists in French for Québec residents who are mostly French speakers).

We are going to show you some simple insurance policies and ask you to rate those. You can assume that if you were to have two or more limitations in activities of daily living, the insurance company offering you this product would pay the benefits no matter what the circumstances. Once you receive benefits, you do not pay any premiums.

Each product has three attributes: a) a monthly premium you have to pay; b) a monthly benefit if you have 2 or more limitations in activities of daily living, starting 3 months after your limitations have been verified; and c) a payout to your survivors if you die before age 85. Assume that if you are healthy and you stop paying premiums for 3 consecutive months, the contract is cancelled and you lose coverage. The premium cannot increase once you have

\footnotetext{
${ }^{9}$ Asking Canadians validates completed questionnaires based on a number of indicators, such as the time of completion, and drops respondents whose answers appear questionable.
} 
purchased the product. Finally, the benefits are adjusted for inflation (indexed).

We presented scenarios using the following representation (with $p, b_{l t c}$ and $b_{l i f e}$ replaced by values in Canadian dollars):

\begin{tabular}{ccc}
\hline While healthy & Once you have at least 2 ADLs & When you die \\
You pay $p$ & You receive $b_{l t c}$ & Your survivors receive $b_{l i f e}$ \\
\hline
\end{tabular}

We use a simple LTCI contract on purpose. In order to avoid uncertainty about the future premiums we explicitly mention that premiums could not increase once the contract is signed. This means of course that real premiums are decreasing. We also insisted on the possibility of lapse-risk in the sense that respondents were made aware that if a payment was not made for some time, it would lead to the termination of the contract. We mentioned that there is no risk regarding payment of benefits. This meant that if the respondent had two or more ADL impairments, then the insurance company would for sure pay the benefits that were contracted upon. We also insisted that the product is offered by a trusted insurance company. We explicitly wanted respondents to dismiss the risks associated with nit-picky insurers (see Bourgeon and Picard (2014)) and the insurer's credit risk; in other words, we wanted to avoid having them think of payment risk. Finally, LTCI benefits are indexed to inflation. Apart from wanting to offer a situation that replicates reality (i.e., LTCI protection is usually indexed to inflation), we also wanted respondents to know that the amount of LTC services they would receive is independent of when they become disabled.

We presented five of those scenarios to each respondent. Each time we asked respondents for the likelihood with which he or she would purchase this product if it were offered by a trusted insurance company. Possible answers ranged from 0\%, meaning there was no chance whatsoever that the respondent would purchase the LTCI product, and $100 \%$, meaning that the respondent would certainly purchase that product. ${ }^{10}$ We consider jointly LTCI and term life insurance contracts because of the potential desirability of having some life insurance protection in case one dies early, prior to facing significant disability risk. ${ }^{11}$ This bundling may be particularly

\footnotetext{
${ }^{10}$ For analysis we re-scale those responses to be between zero and one.

${ }^{11}$ Note, however, that insurance products in which LTC and life insurance benefits are bundled are still not very common in Canada, even though bundled products that include LTC insurance have been discussed for a long time in the scientific community. In particular, these products offer a combination of annuities with LTC (Getzen, 1988; Webb, 2009; Brown and Warshawsky, 2013; Glenzer and Achou, 2019) as well as universal life insurance plans to which policyholders add the right to purchase at set dates (say at the $5^{\text {th }}$ and $10^{\text {th }}$ year policy anniversary) home care insurance coverage. These are known as fu-
} 
interesting for respondents who have some bequest motive. The reason we asked for probabilities is that they convey considerably more information than a yes or no answer and allow to account for the fact that scenarios are incomplete (Manski, 1999). One advantage of asking for the probability with which one would purchase a contract is that we can use these probabilities directly in our analysis without having to make any assumptions about the functional form that leads to a yes/no answer. ${ }^{12}$

Each scenario is constructed in the following way. For each respondent, a monthly LTCI benefit $b_{l t c}$ is first randomly picked from the distribution $[2000,1 / 3 ; 3000,1 / 3 ; 4000,1 / 3]$. We also pick randomly a benefit for the life insurance component of scenario, $b_{l i f e}$ from the distribution $[0,3 / 5 ; 10000,1 / 5,25000,1 / 5]$. In Canada, most insurers only use information on age and gender to price this type of insurance. Some insurers will underwrite insurance on the basis of pre-existing medical conditions but premiums are not a function of health status. In our research design, we therefore concentrate on offering premiums consisting of an age-gender actuarial premium, computed from a microsimulation model, and a price adjustment factor which is randomized but centered on 1 . Hence, the average premium offered to respondents of a certain age and gender group is equal to the actuarial premium we compute from our microsimulation approach. Hence, we first use the health microsimulation model COMPAS, which we describe below, to compute by age and gender the actuarial premium associated to these benefits, assuming a $3 \%$ discount rate. These premiums can be compared to those observed in the market. We obtained from CAA-Québec (which is the Québec equivalent of the AAA in the United States) premium data corresponding to similar levels of coverage to those presented to respondents. In Table 1, we report average estimates in the sample. These premiums are close to those observed in the market, although our model estimates are higher than market premiums for men in general, and for women at younger ages. They are, however, lower for women at older ages. We conclude from this exercise that our modelling of disability risk is close to that used by insurance companies in the industry.

ture purchase option benefits (see, for instance, www.rbcinsurance.com/files/00105/file-105623.pdf; file last retrieved 23 October 2019). In the United States, 260,000 so-called life-LTC hybrid policies were sold in 2017, compared to only 70,000 stand-alone LTCI policies (www.forbes.com/sites/jamiehopkins/2018/ 10/10/hybrid-life-insurance-policies-increasingly-popular-as-long-term-care-funding-strategy/ \#24a1fac61efa; file last retrieved 23 October 2019).

${ }^{12}$ Note that waiting to purchase LTCI has no significant option value. On the opposite, waiting runs the risk of sizeable increases in the insurance premium as agents grow older. Also, there is little reclassification risk (the premium is fixed for the duration of the contract and the lump-sum payment is made conditional on suffering from at least two ADL, irrespective of the severity of dependency). 
We denote by $\bar{c}_{h}$ the actuarial premium for each class of risk (by gender and age), $h$, representing the expected cost expressed monthly for the expected duration of the contract. Finally, we create exogenous variation in premiums by drawing a factor $\tau$ from the vector $(0.6,0.8,1.0,1.2,1.4)$ with probability $1 / 5$ for each element.

The premium is given by $p=\tau \bar{c}_{h}$. Hence a scenario consists of a triple $\left(p, b_{l t c}, b_{\text {life }}\right)$. Each respondent is offered five scenarios, drawn at random as explained above.

\subsection{COMPAS}

There is no detailed projection of disability risk in Canada that would allow us to construct personalized risk estimates for respondents in our survey. We use the microsimulation model COMPAS that was developed to project the long-term evolution of health and health care use in Canada (Boisclair et al., 2016). ${ }^{13}$ The structure of the model follows from other models such as the Future Elderly Model (Goldman et al., 2005). Each individual in the model has many characteristics :

- Socio-demographic characteristics: age, sex, immigration status, education level, income bracket

- Diseases: diabetes, high blood pressure, heart diseases, stroke, cancer, lung diseases, dementia

- risk factors: smoking, obesity

- Disability: limitations in ADLs and Instrumental ADLs (IADL)

- Long-term care: formal home care, nursing home

Based on these characteristics, the core of the model consists of a Markovian transition model of diseases, risk factors, disability and long-term care characteristics. These transitions are based on a set of transition models which were estimated using the National Population Health Survey (1994-2010). The transition model has been satisfactorily tested by simulating on original 1994 data the trajectories of respondents in the NPHS until 2010 and comparing distribution of outcomes. The model delivers simulated life-trajectories conditional on a set of initial conditions. Given the large number of variables, one cannot construct a transition matrix across all these states. Instead, each respondent can be simulated a large number of times and

\footnotetext{
${ }^{13} \mathrm{~A}$ detailed description of the model can be found here.
} 
an individualized set of disability and mortality risks can be computed by averaging over these simulations. When designing the questionnaire for our survey, we deliberately asked questions we could then feed directly into the health transition matrix of COMPAS. In particular, we asked respondents for their education level, their health conditions (same as in COMPAS) and smoking habits. Nevertheless, data limitations are likely to impact some of the calculations we make. COMPAS uses NPHS data which records the location of respondents at the time of the survey but no location is available when the respondent has been found to have died. Since nursing home stays tend to occur more frequently at the end of life, this could impact our estimates. Hurd et al. (2017) find that shorter stays, in particular those near the end of life are missed by core interviews in the Health and Retirement Study. Although short stays may be missed, they may matter more for policyholders than for insurers, as these stays are typically shorter than the deductible threshold of LTCI policies (3-5 months). In particular, it may be that we underestimate the individual risks while respondents have correct expectations about such risks.

Hence, we are able to construct a distribution of individualized disability and mortality risks as a function of a large number of characteristics. Since insurers do not use these characteristics to price LTCI products, we will be able to use these unused pricing characteristics to test for asymmetric information and quantify its effect on take-up of LTCI.

\section{Descriptive Evidence}

We first focus on describing who has or not LTCI in our survey, and on their stated reason for (not) buying it.

\subsection{Take-Up, Knowledge and Awareness of LTCI}

Table 2 reports the number of people with (the rightmost column) and without (the leftmost column) LTCI. We find that the take-up rate of LTCI is low, at $10.5 \%$, at a similar level as that found in the U.S (around 10.8\% in 2009, see Brown and Finkelstein, 2009). We also report the respondents' level of knowledge about LTCI products. Among those who did not purchase LTCI, $39.8 \%$ reported having no knowledge about the product, and $7.9 \%$ reported not knowing what the product was. Others judged that such policies were too expensive $(19 \%)$ or unnecessary $(14 \%)$. 
Among the respondents who were covered by LTCI, close to two-thirds (65\%) knew little about that type of products whereas $5.5 \%$ said they knew nothing at all. The main reason for having purchased an LTCI policy is that they were offered one through one channel or another: only $9.2 \%$ of respondents having an LTCI policy declared having actively searched for such a protection while $53.4 \%$ were offered the product, suggesting that the main channel for obtaining LTCI is likely to be through a financial advisor or direct marketing. ${ }^{14}$

The monthly premium paid was $\$ 116$ on average (at the time of the survey, one Canadian dollar was worth the equivalent of 0.75 US dollar) for monthly benefits of the order of $\$ 2,467$ in case of loss of autonomy. Finally, $76 \%$ of LTCI purchasers had some sort of life insurance policy (whether term life or other), whereas $21.3 \%$ did not have one. Hence, life insurance is much more widespread than LTCI.

\subsection{Risks and Perception}

From the microsimulation model, we compute mortality and disability risk for each respondent based on health and socio-demographic characteristics at the time of the survey. For each respondent, we need a set of probabilities of having limitations in activities of daily living at future ages (from the current age of respondent $i$ to age 110) and similarly for survival probabilities. The microsimulation model yields simulated life trajectories for each of the respondents. We estimate a set of simulated probabilities by feeding each respondent 1000 times into the simulator. We use as inputs gender, age, education, smoking status and a set of health variables asked in the survey and used in COMPAS (whether the respondent has had heart disease, diabetes, hypertension, cancer, stroke and mental health problems). In Figure 1, we report the mortality risk for various age groups at the time of the survey. We first compute the expected number of years of life remaining using individual level survival risk. We then order respondents, for each age group, by percentile of the distribution of remaining life expectancy. We report the average mortality risk within each age group and quartile. We see substantial variation in mortality risk at all ages, which predictably becomes more pronounced at older ages. To give an idea of the magnitudes, an individual respondent in the bottom quartile of age bracket 50-54 has a mortality rate at age 85 that is 2.3 times higher than an individual in the top quartile of the same age bracket. This translates into a remaining life expectancy of 28.21 years in the

\footnotetext{
${ }^{14}$ Note that contrary to other countries (such as the U.S.), employer-provided LTCI is extremely rare in Canada.
} 
bottom quartile and 38.3 years in the top quartile. Hence, mortality risk modelling using survey respondent characteristics yields substantial heterogeneity in survival risk.

We conduct a similar exercise for disability risk. In Figure 2, we report estimates for disability risk conditional on having survived to a given age for each age group. We also see substantial heterogeneity in risk by age. A respondent aged 90 faces a probability of being disabled, and thus needing care, of the order of $20 \%$ to $30 \%$. Given these risks, we can estimate the lifetime risk of ever being disabled and that of ever entering a nursing home for at least 1 year. We present these estimates from COMPAS in Figure 3. On average respondents face a probability of being disabled of $56.1 \%$ but this risk is quite heterogeneous in the population. Because nursing home stays are expensive, we also compute the lifetime risk of entering a nursing home. On average respondents face a risk of $26.2 \%$. Again this risk is very heterogeneous in the population.

To get an idea of the financial exposure due to future LTC expenditures, we estimate the net present value of the expenditures associated with formal care and nursing homes for all respondents. To do this, we need estimates of the cost of a year in a nursing home. These costs vary. The annual cost for Québec public nursing homes is $\$ 43,000$ (Boisclair et al., 2016). We use this cost in both Québec and Ontario for illustrative purposes. Of course, respondents never pay the full cost. So we also compute the cost using the user contribution currently set by the Québec and Ontarian governments at roughly $\$ 2000$ per month, which amounts to $\$ 24,000$ per year, out-of-pocket. For formal care, we use an estimate of $\$ 25$ per hour of formal care and the number of hours of formal care predicted from the microsimulation model. Since the Québec government offers a tax credit of roughly $33 \%$ of expenditures, we also compute an out-of-pocket cost measure for formal care expenditures. There is no such credit in Ontario. We then combine these cost estimates with the probabilities presented earlier to estimate net present value measures of these costs (assuming a 3\% real discount rate and no excess inflation in LTC costs). These estimates are shown in Figure 4. If there was no insurance from the government nor the private sector, on average, respondents would face an expected LTC cost of $\$ 30,788$. There is considerable heterogeneity in that risk. More than $10 \%$ of respondents face a net present value of expenditures larger than $\$ 54,000$. If we account for government participation and assume respondents use public care homes, we obtain an average estimate of $\$ 19,582$ for out-of-pocket expenses. Again, more than $10 \%$ face a net present value of liability in excess of $\$ 34,000$. As expected public insurance reduces substantially the dispersion of the financial risk. Yet, for the median respondent, this exposure represents $25.9 \%$ of his/her total 
yearly household income, or $16.2 \%$ of total savings at the time of the survey. Acknowledging that, once in a nursing home, dependent people stay there on average for 5 years (data obtained from COMPAS), we conclude that the residual financial risk is substantial, at least for a large part of the population. ${ }^{15}$

But of course, decisions are based on perceptions of those risks rather than actual risks. In the survey, we asked respondents for their estimate of the probability they would live to age 85. Hence, we can compare that probability to the one we computed with COMPAS. We can do similarly with the probability of spending at least 1 years with ADLs and the probability of ever needing to enter a nursing home. To compare to actual risks, we compute the deviation of subjective expectations with respect to the objective probability computed from COMPAS. A positive deviation indicates that the respondent overestimates the probability while a negative deviation implies that he underestimates it. Results are shown in Figure 5. We find that respondents overestimate their survival probability to live up to age 85 on average (Difference $=$ 0.045), while they underestimate their probability of living at least 1 year with ADLs (Difference $=-0.080$ ). Interestingly however they overestimate their risk of ever entering a nursing home by 10 p.p. but one should take into account that risks computed for COMPAS exclude short stays particularly at the end of life. ${ }^{16}$ It is important to note that there is considerable heterogeneity in these risk perceptions. Furthermore, a large fraction of respondents have trouble forming probabilities on those events. For example, $35 \%$ of respondents could not provide a probability of the risk of living at least one year with an ADL and $32 \%$ could not report it for nursing home. This number was only $17 \%$ for survival risk. Hence, for those who formed probabilities we find widespread misperception and a significant fraction who have not formed probabilities over those events.

\subsection{Stated-Preference Choice Probabilities}

As shown in Table 3, overall, only $23.6 \%$ of respondents declare they have a zero-probability to buy all five LTCI contracts proposed to them. In other words, $76.7 \%$ of respondents declare a positive probability to buy at least one of these 5 contracts.

In Table 4, we report the average choice probability for each combination of benefits for LTC

\footnotetext{
${ }^{15}$ The average length of time with one ADL or more is on average 4 years.

${ }^{16}$ Similarly, Finkelstein and McGarry (2006) compare the subjective probability of entering a nursing home within 5 years for respondents aged on average 78 to the actual decisions of the same respondents after 5 years. They find that most respondents do not estimate correctly their true probability of entering a nursing home.
} 
and for life insurance. Interestingly, choice probabilities decrease with the level of LTC benefit while they increase with the level of life benefit (except for the contract with the highest LTC benefit). This may suggest that on average respondents prefer lower LTC benefits, perhaps because of crowding-out from public insurance. This also suggests that there may be a joint preference for life and LTC benefits, at least for the contract with a low LTC benefit. The most popular contract appears to combine a monthly LTC benefit of $\$ 2000$ with a Life insurance benefit of $\$ 25,000$. Of course, the variation in equilibrium take-up could vary differently since costs vary across contracts.

\section{Model}

To understand the interplay between demand and supply constraints, we build a simple model following the framework of Einav et al. (2010). Results from the survey suggest that the fraction of respondents who own LTCI is low and that a significant fraction of respondents who do not have LTCI has limited awareness of the product. We integrate in this framework different types of demand-side frictions following Handel et al. (2019). The last component of our survey aims at eliciting preferences for LTCI products. We use elicited choice probabilities to construct estimates of demand as a function of the premium each respondent was given in the survey. Since premiums were randomized conditional on the actuarial premium (based on gender and age), this provides exogenous variations from which we can identify the demand function. Using this identified demand function, and assuming competition in the LTCI market, we can then construct an estimate of the supply curve (using estimates from COMPAS) and compare market equilibrium under selection with the social optimum. This framework also allows us to construct counterfactuals to study the reasons behind low demand.

\subsection{Demand}

There are 9 possible pairs $\left(b_{l t c}, b_{l i f e}\right)$ that can be offered to participants (see section 2.1). Each pair corresponds to a LTCI contract $j$ with $j=1, . ., 9$. For each respondent $i$, we draw at random 5 combinations of a contract $j_{t}$ and a premium $p_{i, t}=\tau_{i, t} \bar{c}_{h, j_{t}}$. The multiplying factor $\tau_{i, t} \in\{0.6,0.8,1.0,1.2,1.4\}$ is randomly chosen and exogenous to the characteristics of the individual, while $\bar{c}_{h, j_{t}}$ is the actuarial premium, under contract $j_{t}$, for the risk class $h$ defined by gender and age groups to which agent $i$ belongs. For each individual, we then have five 
observations of a choice probability $q_{i, t}$ that she buys a LTCI contract $j_{t}$ if it is offered at a price $p_{i, t}$.

We remain agnostic about the origin of these choice probabilities, but they may well originate from a well-defined expected utility model. Although approximating choice probabilities ultimately involves giving up on some of the non-linearity a well-defined structural model would bring, we use a flexible demand model that can be estimated from the data. Let (censored) demand be represented by:

$$
q_{i, t}=\max \left(0,-\alpha\left(\mathbf{x}_{i}, \mathbf{z}_{i, t}, \eta_{i}\right) p_{i, t}+\mu\left(\mathbf{x}_{i}, \mathbf{z}_{i, t}, \nu_{i}\right)+\epsilon_{i, t}\right)
$$

where $\alpha(\cdot)$ controls price sensitivity of demand. $\alpha(\cdot)$ is a function of 1-a set of taste shifters, $\mathbf{x}_{i}$, 2-a set of dummy variables for the contract offered to respondent $i$ in choice situation $t, \mathbf{z}_{i, t}$, and 3 -an unobserved (to us) component $\eta_{i} \sim N\left(0, \sigma_{\eta}^{2}\right) .{ }^{17}$ To insure well-behaved demand curves, we choose a specification that restricts price responses to be negative $(\alpha(\cdot)>0)$ :

$$
\alpha\left(\mathbf{x}_{i}, \mathbf{z}_{i, t}, \eta_{i}\right)=\exp \left(\mathbf{x}_{i} \psi+\mathbf{z}_{i, t} \delta+\eta_{i}\right)
$$

The demand intercept $\mu(\cdot)$ is given by

$$
\mu\left(\mathbf{x}_{i}, \mathbf{z}_{i, t}, \nu_{i}\right)=\mathbf{x}_{i} \beta+\mathbf{z}_{i, t} \gamma+\nu_{i}
$$

with $\nu_{i} \sim N\left(0, \sigma_{\nu}^{2}\right)$. Finally, $\epsilon_{i, t} \sim N\left(0, \sigma_{\epsilon}^{2}\right)$ represents randomness associated with each choice situation which could, for example, account for uncertainty regarding the description of the scenarios (Manski, 1999). The parameters of this model, $\theta=\left(\beta, \gamma, \delta, \psi, \sigma_{\nu}, \sigma_{\eta}, \sigma_{\epsilon}\right)$, can be estimated by maximum simulated likelihood (Hajivassiliou and Ruud, 1994). Upon estimating parameters, we can construct a posterior mean for $\left(\nu_{i}, \eta_{i}\right)$, the unobserved heterogeneity terms, using Bayes' rules and the likelihood. We provide details on the likelihood in Appendix B.

This demand model can be used at the respondent level to get an estimate of demand in counterfactual situations denoted $q_{i, j}\left(\tau \bar{c}_{h, j}\right){ }^{18}$ In particular, we will be interested in situations where some of the factors measuring knowledge frictions and risk perceptions included in $\mathbf{x}_{i}$ are

\footnotetext{
${ }^{17}$ We chose to censor only from below (at zero) and not at one because there is no evidence of bunching at probability one.

${ }^{18}$ We drop the subscript $t$ on contracts when we consider counterfactual demands.
} 
neutralized. We include in $\mathbf{x}_{i}$ a large number of measures we obtain from the survey.

We include a set of socio-economic and health controls: dummies for risk classes (age and sex), whether the respondent lives in Québec, educational attainment, number of kids and, whether the respondent is married. We then add measures of savings and income. We also include a dummy for home ownership. These serve as basic controls for the socio-economic background of respondents. We also control for both expected number of years alive and disabled using microsimulation estimates for each respondent. This controls for the respondent's health status. We also control for the subjective probability that the family takes care of the respondent, and we include a dummy for whether respondents do not know this probability. This proxies for the family network of the respondent as well as for joint preferences for family.

In terms of preferences, we include three variables. First, we asked respondents whether they think that parents should set aside money to leave to their children once they die, even if it means somewhat sacrificing their own comfort in retirement. We create an indicator variable taking value one if they strongly agree or agree. We take this as an indication that the respondent's bequest motive may be driven by some underlying norm or value that leaving a bequest is desirable. We also asked them whether it is the responsibility of the family, when feasible, to take care of parents. We create a similar indicator variable. Finally, we asked respondents about their willingness to take risk. We create an indicator variable taking value one if the respondent is unwilling to take substantial or above average financial risk expecting higher returns. These preference variables are coarse and, compared to a structural model, their effect to predict demand is limited. However, they provide some useful indication of whether standard preferences are predictive of demand for LTCI.

To account for risk misperceptions, we include the deviation between subjective (i.e., reported) and objective (i.e., computed with microsimulation) expected risks of survival, of becoming disabled and of entering a nursing home. We also include indicator variables for whether respondents reported not to know the answers to these questions.

To measure knowledge of the institutions, we include an indicator variable for whether respondents understand that receiving private insurance benefits may influence the fee they pay for subsidized LTC (crowding out). We include the amount they think a nursing home costs, as well as an indicator variable if they do not know these costs, and another indicator variable coding whether they think nursing homes are free. We also include their evaluation of the average waiting time for a place in a subsidized home (relative to the actual average waiting 
time), and an indicator variable if they do not know waiting times.

Since, we observe that a large fraction of respondents know little or nothing about LTCI we include controls for awareness of the product. We include two dummy variables taking the value one if they respond they know little and nothing, respectively.

\subsection{Supply}

We construct synthetic cost estimates using the microsimulation model we outlined in Section 2.2. Denote by $d_{i, a}$ the estimated disability risk of respondent $i$ at age $a$ and by $s_{i, a}$ the survival probability to age $a$. Voluntary lapsing occurs, i.e., respondents may stop payments and terminate their contract. We account for lapsing using an estimate of the fraction of contracts that voluntarily lapse each year from the Society of Actuaries (see Appendix A). The fraction of LTCI customers who lapsed in 2011 was 1.8\%. Since this fraction does not appear to differ by gender nor age, we use this uniform estimate. Denote by $z_{i, a}=(1-0.018)^{a-a g e_{i}}$ the survival rate of the contract owing to lapsing. We also set the real discount rate to $\rho=0.03$ and the inflation rate to $\iota=0.02$ (since premiums remain constant in nominal terms). We can then compute the expected discounted cost, for the insurers, of respondent $i$ buying contract $j$ as

$$
C_{i, j}=\sum_{a \geq a g e_{i}} \frac{1}{(1+\rho+\iota)^{a-a g e_{i}}} z_{i, a}\left(s_{i, a} d_{i, a} b e n_{l t c, j}+m_{i, a} I_{(a<85)} b e n_{l i f e, j}\right),
$$

where $m_{i, a}=1-s_{i, a} / s_{i, a-1}$ is the mortality rate at age $a$ and $I_{(a<85)}=1$ when $a<85$.

We plot on Figure 7 the distribution of costs, $C_{i, j}$, for the 9 contracts offered to respondents. The median expected cost ranges from $\$ 20,265$ for the contract offering a monthly LTC benefit of $\$ 2,000$ and no life insurance benefit to $\$ 46,515$ for the contract offering a $\$ 4,000$ monthly LTC benefit and a $\$ 25,000$ life insurance benefit. We observe substantial variations in the individual costs for any given contract. The largest variation occurs in the case of contracts that bundle life insurance with LTCI benefits. For instance, for a monthly LTC benefit of $\$ 3,000$ and a $\$ 10,000$ life insurance benefit, expected cost to the insurer ranges from $\$ 19,685$ to $\$ 44,481$ at the $95^{\text {th }}$ percentile.

We express the total expected discounted cost in terms of the equivalent monthly actuarial 
premium, denoted by $c_{i, j}$. The two quantities are related by $C_{i, j}=\Pi_{i} c_{i, j}$ where

$$
\Pi_{i}=\sum_{a \geq a g e_{i}} \frac{1}{(1+\rho+\iota)^{a-a g e_{i}}} z_{i, a} s_{i, a}\left(1-d_{i, a}\right)
$$

is the present value of one dollar of actuarial monthly premium. Therefore, the actuarial premium $c_{i, j}=C_{i, j} / \Pi_{i}$ is the constant monthly payment the insurance company would need to obtain from consumer $i$ in order to satisfy the zero expected profit condition.

In the Canadian market, risk classification is based on gender and age. Denote by $h$ a risk class (say 50-54 men) and $H$ the set of risk classes. The average monthly cost of those who purchase the contract $j$ in risk group $h$ is obtained using information on the cost for each respondent and the choice probabilities,

$$
A C_{h, j}\left(\tau_{h, j}\right)=\frac{1}{\bar{q}_{j}\left(\tau_{h, j} \bar{c}_{h, j}\right)} \sum_{i \in h} c_{i, j} q_{i, j}\left(\tau \bar{c}_{h, j}\right)
$$

where $c_{i, j}$ is obtained from above, $\bar{c}_{h, j}$ is the average cost for risk group $h$ in contract $j$ to which individual $i$ belongs, and $\bar{q}_{j}$ is the fraction of insured individuals with contract $j$. Adverse selection arises when there is a positive correlation between expected cost and demand at the respondent level. Indeed, this is the case if riskier agents (and hence more costly agents) buy more insurance. This leads to a positive relationship between $A C_{h, j}(\tau)$ and $\tau$. To the opposite, when there is a negative correlation, i.e. less risky agents buy more insurance, propitious (or advantageous) selection arises. Hence a direct test of selection can be conducted from these hypothetical data. Ideally, $c_{i, j}$ would be estimated from realized claims which would allow for more heterogeneity in cost and hence a higher potential for selection. Despite our rich characterization of individual level expected cost, it is possible that we miss some of the selection which may be present in reality. However, there is considerable variance in the cost and revenue estimates within sample and it is sufficient to allow us to test for selection based on the characteristics we account for.

\subsection{Competitive Equilibrium}

The monthly premium is $p_{h, j}=\tau_{h, j} \bar{c}_{h, j}$ and $\tau_{h, j}$ is the multiplying factor yielding the market premium. Following Einav et al. (2010), perfect competition drives insurer profits to zero, thus 
implying that the equilibrium $\tau_{h, j}^{*}$ solves

$$
\tau_{h, j}=\frac{1}{\bar{c}_{h, j}} A C_{h, j}\left(\tau_{h, j}\right)
$$

where $A C_{h, j}\left(\tau_{h, j}\right)$ is the average cost of agents $i$ belonging to class $h$ who therefore purchase the contract within class $h$. The equilibrium fraction of respondents insured in class $h$ is then $\bar{q}_{h, j}\left(\tau_{h, j}^{*} \bar{c}_{h, j}\right)$.

While we will provide a comparison between the case where $\tau_{h, j}$ is allowed to vary across risk classes, we will assume for graphical representation of the equilibrium that $\tau_{h, j}=\tau_{h^{\prime}, j} \forall h, h^{\prime} \in H$. We refer to this situation as uniform pricing. Note that even if $\tau$ is the same across risk classes, premiums are not as they depend on $\bar{c}_{h, j}$. Assuming uniform pricing allows for a graphical representation of the overall equilibrium in terms of demand and supply in the space $(\tau, q)$. The competitive equilibrium $\tau_{j}^{*}$ solves:

$$
\tau_{j}=\frac{1}{\bar{c}_{j}} A C_{j}\left(\tau_{j}\right)
$$

where $\bar{c}_{j}$ is the average cost over the whole population of potential customers and where

$$
A C_{j}\left(\tau_{j}\right)=\frac{1}{\sum_{h} \bar{q}_{j}\left(\tau_{j} \bar{c}_{h, j}\right)} \sum_{h} \sum_{i \in h} c_{i, j} q_{i, j}\left(\tau \bar{c}_{h, j}\right)
$$

We will refer to $\overline{A C}_{j}:=A C_{j}\left(\tau_{j}\right) / \bar{c}_{j}$ as the normalized average cost. There is adverse selection when the normalized average cost is above unity, i.e., $\tau_{j}^{*}>1$, reflecting an overall positive covariance between demand and cost at the individual level. Conversely, there is advantageous selection when $\tau_{j}^{*}<1$.

The competitive equilibrium without frictions is computed similarly as above replacing $q_{i}(\cdot)$ with $\hat{q}_{i}(\cdot)$ which uses counterfactual $\widehat{\alpha}_{i}=\alpha\left(\hat{\mathbf{x}}_{i}, \mathbf{z}_{i, t}, \eta_{i}\right)$ and $\widehat{\mu}_{i}=\mu\left(\hat{\mathbf{x}}_{i}, \mathbf{z}_{i, t}, \eta_{i}\right)$ without frictions,

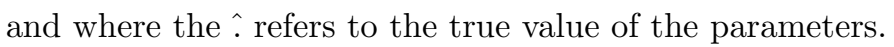

\subsection{Welfare in the Competitive Equilibrium}

To simplify notation, we henceforth drop the subscript $j$ referring to the type of contract. Demand for individual $i$ is

$$
q_{i}\left(p_{i}\right)=\max \left(0,-\alpha_{i} p_{i}+\mu_{i}\right)
$$


where $\alpha_{i}$ and $\mu_{i}$ are shorthand for the parameters in equation 1 that depend on the individual's characteristics (and contract type) and $p_{i}$ is the price faced by the individual. We interpret $q_{i}\left(p_{i}\right)$ as the proportion of individuals with characteristic $i$ purchasing the contract. This allows us to use standard welfare formulas except that the value to consumers is computed on the basis of the marginal value curve

$$
\widehat{q}_{i}\left(p_{i}\right)=\max \left(0,-\widehat{\alpha}_{i} p_{i}+\widehat{\mu}_{i}\right)
$$

where $\widehat{\alpha}_{i}$ and $\widehat{\mu}_{i}$ are the counterfactuals without informational frictions.

At the price $p_{i}$, the total value to consumers with characteristic $i$ is the area under the marginal value curve up to $q_{i}\left(p_{i}\right)$. This is computed as follows. Consumers behaving on the basis of the true marginal value curve (9) would purchase a positive quantity $q_{i}\left(p_{i}\right)$ if they faced a price $\widehat{p}_{i}$ satisfying

$$
-\widehat{\alpha}_{i} \widehat{p}_{i}+\widehat{\mu}_{i}=-\alpha_{i} p_{i}+\mu_{i}
$$

We take it that $\widehat{p}_{i}$ is positive, i.e., eliminating frictions would not reduce demand by too much (and may in fact increase it). The total value of $q_{i}\left(p_{i}\right)$ to consumers is then

$$
V_{i}\left(q_{i}\left(p_{i}\right)\right)=\int_{\widehat{p}_{i}}^{\infty} \widehat{q}_{i}(p) d p+\widehat{p}_{i} q_{i}\left(p_{i}\right)
$$

Straightforward computations yield

$$
V_{i}\left(q_{i}\left(p_{i}\right)\right)=\frac{1}{2} q_{i}\left(p_{i}\right)\left(\frac{\alpha_{i} p_{i}+2 \widehat{\mu}_{i}-\mu_{i}}{\widehat{\alpha}_{i}}\right)
$$

Note that the latter expression is zero when consumers with characteristic $i$ do not purchase the contract.

Welfare is the sum of values to consumer minus the total cost of providing the insurance policy:

$$
W=\sum_{i}\left[V_{i}\left(q_{i}\left(p_{i}\right)\right)-c_{i} q_{i}\left(p_{i}\right)\right] .
$$

In the competitive equilibrium, $p_{i}=\tau^{*} \bar{c}_{h}$ for $i$ in the gender-age class $h$ and where $\tau^{*}$ solves (6). Welfare at equilibrium can then be expressed as

$$
W^{e q}=\sum_{h} \sum_{i \in h}\left[V_{i}\left(q_{i}\left(\tau^{*} \bar{c}_{h}\right)\right)-c_{i} q_{i}\left(\tau^{*} \bar{c}_{h}\right)\right] .
$$




\subsection{Optimum}

We consider a variant of the efficient uniform price discussed in the literature. ${ }^{19}$ Individuals $i$ in the age-gender class $h$ face the price $p_{i}=\tau \bar{c}_{h}$ where $\tau$ is now chosen to maximize the welfare of potential purchasers over all age-gender classes. Welfare is computed with consumers behaving on the basis of their true marginal value. At price $p_{i}$, and using (10), the total value to consumers $i$ is

$$
V_{i}\left(\widehat{q}_{i}\left(p_{i}\right)\right)=\int_{p_{i}}^{\infty} \widehat{q}_{i}(p) d p+p_{i} \widehat{q}_{i}\left(p_{i}\right)
$$

Using (11), this is easily seen to reduce to

$$
V_{i}\left(\widehat{q}_{i}\left(p_{i}\right)\right)=\frac{1}{2} \widehat{q}_{i}\left(p_{i}\right)\left(p_{i}+\frac{\widehat{\mu}_{i}}{\widehat{\alpha}_{i}}\right)
$$

Total welfare is now given by

$$
W=\sum_{i}\left[V_{i}\left(\widehat{q}_{i}\left(p_{i}\right)\right)-c_{i} \widehat{q}_{i}\left(p_{i}\right)\right]
$$

Substituting for $p_{i}=\tau \bar{c}_{h}$ and maximizing with respect to $\tau$, optimal welfare is

$$
W^{o p}=\max _{\tau} \sum_{h} \sum_{i \in h}\left[V_{i}\left(\widehat{q}_{i}\left(\tau \bar{c}_{h}\right)\right)-c_{i} \widehat{q}_{i}\left(\tau \bar{c}_{h}\right)\right]
$$

The optimal mark-up (or mark down) is denoted $\tau^{* *}$.

In the next section, for any given contract, we show figures comparing the competitive equilibrium and the optimum with $\tau$ on the vertical axis and total quantity on the horizontal axis, where quantity is on the basis of the demand with or without frictions. ${ }^{20}$ As $\tau$ is not a price strictly speaking, the figures warrant some explanation. A given $\tau$ yields a total quantity distributed between purchasers with different characteristics. To this quantity can be associated an average cost, normalized by the average cost over all potential purchasers as in equation (6). The normalized average cost may differ depending on whether the demand is with or without frictions because actual purchasers will sort differently. To draw marginal cost curves consistent with these figures, we also need to introduce an appropriate normalization. This allows, in

\footnotetext{
${ }^{19}$ See Einav et al. (2010) and Dardanoni and Li Donni (2016). The uniform efficient price, also described as the constrained efficient benchmark, occurs when the marginal cost curve crosses the demand curve.

${ }^{20}$ In the figures, the quantity is the fraction of potential customers who purchase the policy.
} 
particular, the optimal $\tau^{* *}$ to be determined by the intersection of the demand without frictions and the normalized marginal cost given the consumers' behavior.

The first-order condition of problem (13) is

$$
\frac{d \sum_{h} \sum_{i \in h} V_{i}\left(\widehat{q}_{i}\left(\tau \bar{c}_{h}\right)\right)}{d \tau}=\frac{d \sum_{h} \sum_{i \in h} c_{i} \widehat{q}_{i}\left(\tau \bar{c}_{h}\right)}{d \tau}
$$

In words, the change in value owing to a small change in $\tau$ is equal to the change in costs. Note that $\partial V_{i} / \partial \widehat{q}_{i}=\tau \bar{c}_{h}$ for individuals in risk class $h$ and that $d \widehat{q}_{i}\left(\tau \bar{c}_{h}\right) / d \tau=\bar{c}_{h} \widehat{q}_{i}^{\prime}\left(\tau \bar{c}_{h}\right)$, where $\widehat{q}_{i}^{\prime}(\cdot)$ is the derivative of each demand relative to the price. ${ }^{21}$ The first-order condition then implies that the optimal $\tau^{* *}$ solves

$$
\tau=\frac{\sum_{h} \sum_{i \in h} c_{i} \bar{c}_{h} \widehat{q}_{i}^{\prime}\left(\tau \bar{c}_{h}\right)}{\sum_{h} \sum_{i \in h} \bar{c}_{h}^{2} \widehat{q}_{i}^{\prime}\left(\tau \bar{c}_{h}\right)}
$$

We show that the right-hand side of (14) can be interpreted as the normalized marginal cost. Actual marginal cost is

$$
M C(\tau)=\frac{d \sum_{h} \sum_{i \in h} c_{i} \widehat{q}_{i}\left(\tau \bar{c}_{h}\right) / d \tau}{d \sum_{h} \sum_{i \in h} \widehat{q}_{i}\left(\tau \bar{c}_{h}\right) / d \tau}
$$

that is, the change in total cost relative to the change in quantity. This rewrites as

$$
M C(\tau)=\frac{\sum_{h} \sum_{i \in h} c_{i} \bar{c}_{h} \widehat{q}_{i}^{\prime}\left(\tau \bar{c}_{h}\right)}{\sum_{h} \sum_{i \in h} \bar{c}_{h} \widehat{q}_{i}^{\prime}\left(\tau \bar{c}_{h}\right)}
$$

Normalized marginal cost, as defined by the right-hand side of (14), is

$$
\overline{M C}(\tau):=\frac{M C(\tau)}{\gamma(\tau)}
$$

with the normalization factor

$$
\gamma(\tau):=\frac{\sum_{h} \sum_{i \in h} \bar{c}_{h}^{2} \widehat{q}_{i}^{\prime}\left(\tau \bar{c}_{h}\right)}{\sum_{h} \sum_{i \in h} \bar{c}_{h} \widehat{q}_{i}^{\prime}\left(\tau \bar{c}_{h}\right)}
$$

The normalization factor does not depend on individual costs. Only the average cost difference between age-gender classes matter. When all $\bar{c}_{h}$ are equal, i.e., $\bar{c}_{h}=\bar{c}$ for all $h$, then $\gamma(\tau)=\bar{c}$. The normalisation is then the same as for the average cost.

A normalized marginal cost is derived similarly for the case where consumers behave according to their demand with frictions. In Section 5.3, we discuss the case where $\tau$ is specific to each

\footnotetext{
${ }^{21}$ When the demand is positive, $\widehat{q}_{i}^{\prime}(\cdot)=-\alpha_{i}$. When $\tau \bar{c}_{h}>\mu_{i} / \alpha_{i}$, the demand is nil and $\widehat{q}_{i}^{\prime}(\cdot)=0$.
} 
age-gender class. The normalization factor is then equal to $\bar{c}$ and is the same as for the average cost.

\section{Results}

\subsection{Demand Estimation Results}

Estimates of the demand model are reported in Table 5. Given that characteristics affect both intercepts and slopes, their total effect depends on the derivative of demand with respect to these characteristics. Hence, we report average partial effects on demand evaluated at the average premium presented to respondents. ${ }^{22}$

Socio-economic and Health: There are small differences across age and sex for intercepts but significant differences for price sensitivity. Females (in particular those aged 60-64) have in general lower price sensitivity than their male counterparts. At average premiums, females have larger demand than men. College educated individuals are also less price sensitive and therefore have slightly higher demand at average premiums than non college educated individuals. We find no statistically significant differences in terms of marital status. Demand (intercept and price sensitivity) is generally lower for individuals with larger savings and higher income, both of which lead to a higher demand at the average premium.

In terms of expected number of years alive and disabled, only disability appears to impact demand with a lower intercept but also lower price sensitivity, which leads to higher demand at the average premium. Hence, individuals who are expected to have higher LTC costs also have higher demand. Although this is potentially evidence of adverse selection, it is the overall correlation between demand and costs within a risk class, i.e. the risk classification used by insurers, which determines whether or not there is adverse selection (Finkelstein and McGarry, 2006). We come back to this point below.

Individuals who own a home have lower demand but are more price sensitive. As in Davidoff (2009), we obtain that the house may act as a substitute for LTCI as it is mostly non-liquid until individuals either die or move into a nursing home, at which point it can be sold to finance extra LTC spending.

\footnotetext{
${ }^{22}$ For a characteristic $x_{k}$ the average partial effect is $\left(-\sum_{i} \alpha_{i} \bar{p}_{i} \psi_{k}+\beta_{k}\right) P_{i}$ where $\alpha_{i}$ is the predicted slope of respondent $i, \bar{p}_{i}$ is the average premium presented to respondent $i$ over scenarios and $P_{i}$ is the probability that demand is positive. We do the same for contract characteristics $z$.
} 
We find that individuals with a larger probability that the family provides care have slightly higher demand for LTCI. In Canada, the LTCI contract is generally conditioned on care needs rather than on reimbursements (i.e. actual consumption of external LTC services) so that one potential mechanism consists in providing financial relief for children who take care of their parents. ${ }^{23}$ Interestingly, individuals who do not know this probability have higher demand at average premiums. The need to insure against uncertainty regarding family care may raise demand for LTCI. ${ }^{24}$

Preferences: We find that individuals who are more risk averse and those with a bequest motive have lower price sensitivity. However, we do not find differences in intercepts for preferences which leads to positive average partial effects at average premiums. Hence, more risk averse respondents and those with a bequest motive have higher demand for LTCI. This is consistent with bequests raising the need to protect savings from future large LTC expenditures but not with studies finding that bequest motives reduce the opportunity cost of saving and hence generate lower demand for LTCI (Lockwood, 2014). ${ }^{25}$ Those who think the family should care for frail parents have slightly higher demand overall.

Risk Perceptions: Biases in risk perceptions (positive implies pessimism for disability and nursing home and optimism for survival) for disability, survival, and nursing home visits generally lead to less price sensitivity and therefore to higher demand at average premiums. ${ }^{26}$ The results suggest that higher demand is not due to higher intercepts but to lower price sensitivity, something that would be missed if one does not allow for heterogeneous price sensitivity. Generally, individuals who do not know these risks have lower demand.

Knowledge: Individuals who do not know that LTCI crowds-out government benefits have lower demand and lower price sensitivity, which leads to a negative effect on demand at average prices. Hence, crowd-out cannot explain why our respondents do not buy insurance. In Canada, public subsidies, such as lower co-payments for nursing homes and tax credit for formal care, are means-tested, which should reduce the demand for long-term care insurance. ${ }^{27}$

There is little relationship between incorrect knowledge of nursing home cost and demand.

\footnotetext{
${ }^{23}$ For instance, Pinquart and Sörensen (2002) show that dependent individuals in general prefer informal help, or a combination of informal and formal support, to purely formal support, at least for short term needs.

${ }^{24}$ Bonsang (2009) obtains similar results, providing evidence of substitution between informal and formal help, the latter being monetary transfers which mostly result from public or private insurances.

${ }^{25}$ See also Ameriks et al. (2011) about the importance of bequest motives for late-in-life decisions to save.

${ }^{26}$ Studies by Zhou-Richter et al. (2010) and Tennyson and Yang (2014) yield similar results.

${ }^{27}$ Brown and Finkelstein (2008) find that social insurance (in particular Medicaid) crowds out the demand for private insurance.
} 
But individuals who do not know nursing home costs have lower demand and price sensitivity. This is somewhat related to Tennyson and Yang (2014) who highlight the role of one's experience with LTC as a contributing factor to better knowing the risk of LTC costs. Interestingly individuals who do not know waiting times have higher demand, but also larger price sensitivity, which overall also leads to little change in demand. Hence, relatively small overall effects hide important price sensitivity responses, as in the case of crowding-out.

Awareness: In Section 3.1, we have shown that knowledge of LTCI itself is limited. We find that individuals who know nothing about LTCI prior to taking the survey have much lower demand (-3.4\%). Individuals who know little about LTCI have larger price sensitivity which leads to even lower demand at average premiums (-7.6\%).

Contract features: Demand for the different contracts varies. The highest demand is observed for contracts that offer life-insurance benefits relative to those that do not. Demand is also larger for more generous LTCI benefits rather than less generous benefits. Except for one contract out of nine (LTCI benefit of $\$ 2,000$ and life insurance of $\$ 25,000$ ), price sensitivity is similar across contracts.

Unobserved Heterogeneity: Overall, we find substantial unobserved heterogeneity in demand. The standard deviation of unobserved heterogeneity is large for both price sensitivity and intercepts. Hence, substantial variation in price sensitivity and intercepts is left even after controlling for a large set of demand shifters.

We construct individual estimates of $\alpha(\cdot)$ and $\mu(\cdot)$ with and without frictions. Estimates without friction are constructed by zeroing-out risk perception biases, assuming perfect knowledge of institutions (of those measured) and good knowledge of LTCI generally. We denote estimates without frictions, $\hat{\alpha}(\cdot)$ and $\hat{\mu}(\cdot)$. In Figure 6 , we report the distribution of the price sensitivities. We express these parameters as elasticities on censored demand (non-negative demand) for the first contract (since elasticities vary little by contract).

The average elasticity in the sample with frictions is 0.65 with substantial variation across respondents. Without frictions, the price sensitivity is slightly larger at 0.69 . Hence, our respondents have relatively inelastic demand. Only $20 \%$ of respondents have an elasticity above unit (22\% without frictions). In a study using a life-cycle model approach, Ameriks et al. (2016) find comparable results (lower than unity elasticities). Yet, two other studies focus on the impact of tax incentives on individuals' purchase of LTCI and find higher elasticities. Courtemanche and He (2009) study the impact of the tax incentive prescribed in the Health 
Insurance Portability and Accountability Act (HIPAA) of 1996 and find a price elasticity of LTCI of -3.9 suggesting that the demand for LTCI is very price elastic. Also, Goda (2011) examines the effect of a variation in tax subsidies for private LTCI on insurance coverage rates and Medicaid expenditure for LTC. Using HRS data for the period 1996-2006, she finds that implementing tax subsidies on private LTCI yields an implied elasticity of -3.3 .

Hence, our estimates are much smaller than estimates using natural experiments. There are many reasons why this may occur. First, it is possible that hypothetical stated-choice experiments yield lower price responses. Yet, we are not aware of consistent evidence that hypothetical studies underestimate price sensitivity. Second, it is possible that, given the heterogeneity uncovered in price sensitivity, the set of individuals reacting to particular measures is different, which could explain why estimates vary substantially. A third possibility is that tax rebates make price changes explicit (salient) while variation in prices across scenarios do not. If consumers react more, or pay more attention, to explicit changes, this could explain the difference between our estimates and those from natural experiments.

\subsection{Equilibrium Results}

We now investigate the predicted equilibrium in the LTC market for the different contracts we offered. We first look at contracts that do not include a life insurance benefit. For each of these contracts, we construct demand as outlined in Section 4.1 above and compute costs for each respondent as outlined in Section 4.2 which provides us with the average cost curve. We then solve for the equilibrium relative price and quantity as outlined in Section 4.3. We similarly derive the marginal cost function from the average cost function. This allows us to compute the social optimum as shown in Section 4.5, assuming $\tau$ does not vary across risk classes.

Plots of those markets are presented in Figure 8. The equilibrium fraction of respondents who purchase LTCI runs from $20.7 \%$ for the contract offering a $\$ 2,000$ LTCI benefit to $14.2 \%$ for the contract offering a $\$ 4,000$ benefit (with no life insurance benefit component). Hence, the fraction of individuals who would purchase LTCI is low (say relative to life insurance). It remains higher than the actual fraction with LTCI in the sample. One reason is that close to $40 \%$ of those without LTCI were never offered LTCI and did not know about it. If we put their demand to zero, we obtain take-up rates which are consistent with the observed take-up rate. Hence, our experiment yields higher take-up rates simply because we offer contracts to 
respondents.

We do not find evidence of adverse selection. If anything, average cost is sloping upward and the equilibrium relative price is below one. This would indicate evidence of advantageous selection. While health tends to lead to adverse selection (those with higher expected years with disability have higher demand), other characteristics, correlated with costs and demand, but unused in pricing, counteract this effect. As the social optimum without asymmetric information in this case has a lower fraction insured, we can rule out asymmetric information as a reason for the low take-up of LTCI.

The role of information frictions is much larger. Demand without frictions (replacing $\alpha(\cdot)$ and $\mu(\cdot)$ by $\hat{\alpha}(\cdot)$ and $\hat{\mu}(\cdot))$ is much higher at any price. In Figure 8 , we plot demand, average cost and marginal cost without frictions. The equilibrium fraction with LTCI is $30.4 \%, 25.2 \%$ and $20.6 \%$ for the contracts offering $\$ 2,000, \$ 3,000$ and $\$ 4,000$ LTCI benefits respectively. The displacement of demand is for the most part parallel but this hides considerable displacement in terms of who is insured and who is not.

In Figure 9, we report similar market equilibrium plots for contracts with a varying level of the life insurance benefit, keeping constant the LTCI benefit at $\$ 2,000$ per month (similar figures emerge at other levels). We find very similar results with no evidence of adverse selection, some evidence of advantageous selection and a large demand effect of frictions. Demand is slightly larger with a life insurance benefit but that effect is not large. For example, offering a $\$ 10,000$ life insurance benefit, increases equilibrium take-up from $20.7 \%$ to $22.5 \%$. Hence, although we have shown in Table 4 that demand was at least 4 percentage point higher when a life-insurance benefit was offered, a smaller effect is observed in equilibrium, due potentially to costs and selection.

In Table 6, we report the social optimum (i.e. without any supply-side or demand-side frictions) as well as welfare loss due to asymmetric information and information frictions. Overall the social optimum is very close to the competitive equilibrium without frictions, confirming that asymmetric information plays a minor role. In fact, for the contract $(2 K, 0 K)$, the welfare loss due to asymmetric information (AS loss) represents less than $0.012 \%$ of the total social optimum welfare. The role of frictions is much larger. Across contracts, the welfare loss due to frictions is close to $18 \%$ of the total social optimum welfare. In Section 5.4 below, we decompose frictions and quantify their separate impact on total welfare loss in this market. 


\subsection{Equilibrium Results with Segmentation}

In Table 7, we report equilibrium results for each risk class separately (age and gender). There is some evidence that despite having higher demand (see Table 5), the equilibrium take-up ends up being lower among females. But differences are not large. As for age, the equilibrium take-up tends to decrease with age for men while the pattern is less clear for females. One reason why there is variation across risk classes could simply be sampling variation and given that equilibrium calculations are based on a smaller set of respondents within each risk class, differences in simulations appear relatively small. The role of frictions remains important, even within risk class, while the loss due to adverse selection remains very small. In Table 8, we report a comparison of aggregate equilibrium take-up, as well as optimum and welfare losses for the case where we allow pricing to be set within each risk class (segmented) and when it is not (uniform). We always find a higher take up rate under uniform pricing than under segmented pricing. In general we see very small differences when comparing uniform and segmented prices, whether in terms of equilibrium take-up (with and without frictions) or welfare losses from asymmetric information and frictions.

\subsection{Decomposition of Frictions}

As outlined earlier, we consider three types of frictions: risk perceptions, knowledge of institutions, and awareness of LTCI. In Table 9, we report simulations which introduce one friction at a time and compute the effect on equilibrium take-up (Q) as well as the welfare loss associated with it. Risk perceptions have little effect on aggregate take-up despite correlating very well with demand (see Table 5). Indeed, despite risk perceptions being wide-spread in our population, at the aggregate level, positive biases cancel out negative biases so that the average bias in risk perceptions is close to zero. ${ }^{28}$ Overall the welfare loss due to risk perceptions is small (less than $1 \%$ of welfare in the social optimum). Knowledge of institutions and awareness play a much larger role, but that role varies across contracts. The welfare loss due to knowledge seems to be more important when the contract provides larger LTCI and life-insurance benefits. In contrast, the welfare loss due to the awareness that LTCI products exist appears more important for less generous contracts. Interestingly, the effect on equilibrium take-up of removing frictions is not always perfectly correlated with the welfare loss. For example, removing frictions due to

\footnotetext{
${ }^{28}$ For a detailed study of the impacts of risk misperceptions on the decision to buy LTCI, see Boyer et al. (2019b).
} 
knowledge of institutions has a larger effect on equilibrium quantity for less generous contracts but generates smaller welfare losses as a result of these frictions.

To understand the distribution of welfare changes, we compute each respondent's variation in consumer surplus between the equilibrium with frictions and the social optimum. This difference yields a monetary amount in dollar per month. This welfare change measures the potential individual benefit of acquiring information that collectively leads to optimal outcomes. This amount represents the respondents' willingness-to-pay in order to reach the social optimum, i.e. the maximum cost of acquiring information (to remove informational frictions) they are willing to bear. We report in Figure 10 the (cumulative) distribution of those welfare effects. We find that the average welfare cost of moving from optimum to equilibrium is $\$ 9.98$ per month with a large standard deviation. Close to $50 \%$ of respondents have a lower welfare at equilibrium (i.e. a negative number in Figure 10), close to $40 \%$ have similar surplus at equilibrium and at the social optimum and a small fraction are indeed better off at the equilibrium. Given that the price is higher in the social optimum, some of those with higher demand obtain lower consumer surplus when we move to the social optimum. This illustrates that there are winners and losers and that the increase in welfare is not necessarily Pareto improving.

Overall the low cost of ending up at the equilibrium with frictions, rather than at the social optimum, means that agents should have a low willingness-to-pay for removing informational frictions. This low willingness-to-pay is a viable explanation for the persistence of informational frictions.

\section{Conclusion}

In this paper, we provide new evidence on the determinants of low take-up rate of long-term care insurance in Canada using stated choice probabilities. The typical LTCI product in Canada differs somewhat from what is observed in the U.S. For example, most insurance companies offer a benefit paid on the basis of ADL limitations rather than reimbursing expenses for LTC. We exploit exogenous variation in prices across various scenarios differing on benefit structure to derive predictions for equilibrium under selection as in Einav et al. (2010). Since we ask directly about choice probabilities, we remain agnostic about the exact model that generates demand. With results from our baseline predictions, we then construct a number of counterfactuals correcting for a number of frictions (risk perceptions, knowledge and awareness) in this market. 
We estimate the welfare losses associated to these frictions as in Handel et al. (2019).

Our key results are threefold. First, we find that part of the explanation for low take-up is simply that the near elderly, the prime target group, have limited awareness of the product, limited knowledge of the institutions, and biased perceptions about the costs and the risks surrounding LTC. Compared to a baseline projected fraction of the population of $20 \%$ that has access to a $\$ 2,000$ monthly LTC insurance benefit, a counterfactual where we correct for frictions yields a take-up rate closer to $30 \%$. Hence, information constraints (in particular knowledge of institutions and costs, and awareness of the LTCI products) play a large role. Second, we find evidence of weak advantageous selection, based on observed health status unused in pricing. Yet, this effect is very small in equilibrium. Third, exploiting exogenous variation in prices from the survey design, we estimate average price elasticities typically below one (-0.65) with less than $20 \%$ of respondents having elasticities below -1 . This is in contrast to existing estimates in the literature (Courtemanche and He, 2009; Goda, 2011) but consistent with evidence presented in Ameriks et al. (2016).

Although we find that there would be important potential welfare gains from increased awareness of the products and knowledge of institutions in this market, our study suggests that there is limited scope for take-up to reach levels beyond 30\%. We can think of three reasons why take-up may be low relative to what one would expect in other contexts. First, public provision of LTCI, e.g. through reduced user fees, shields consumers from a substantial part of the risk, in contrast to the U.S. where only low income (and asset poor) consumers can benefit from subsidized LTC services. Second, older Canadians have a generous safety net which provides substantial income replacement rates for a significant portion of the population. Third, individuals could value consumption less when needing care than when healthy, even though empirical evidence on this channel is still rather unclear; Ameriks et al. (ming) find estimates that would suggest higher marginal value of money when in need of LTC while Finkelstein et al. (2013) find that the contrary when evaluating marginal utility in case of chronic diseases. 


\section{References}

Ameriks, J., Briggs, J., Caplin, A., Shapiro, M. D., and Tonetti, C. (2016). The long-term-care insurance puzzle: Modeling and measurement. Working Paper 22726, National Bureau of Economic Research.

Ameriks, J., Briggs, J. S., Caplin, A., Shapiro, M. D., and Tonetti, C. (forthcoming). Long term care utility and late in life saving. Journal of Political Economy.

Ameriks, J., Caplin, A., Laufer, S., and Van Nieuwerburgh, S. (2011). The Joy of Giving or Assisted Living? Using Strategic Surveys to Separate Public Care Aversion from Bequest Motives. The Journal of Finance, 66(2):519-561.

Boisclair, D., Cote-Sergent, A., Laliberte-Auger, F., Marchand, S., and Michaud, P.-C. (2016). A health microsimulation model for Quebec and Canada. Technical report, HEC Montreal CEDIA.

Bommier, A. and Grand, F. L. (2014). Too risk averse to purchase insurance? a theoretical glance at the annuity puzzle. Journal of Risk and Uncertainty, 48(2):135-166.

Bonsang, E. (2009). Does informal care from children to their elderly parents substitute for formal care in Europe? Journal of Health Economics, 28(1):143-154.

Bourgeon, J.-M. and Picard, P. (2014). Fraudulent claims and nitpicky insurers. American Economic Review, 104(9):2900-2917.

Boyer, M. M., De Donder, P., Leroux, M.-L., Fluet, C., and Michaud, P.-C. (2019a). A canadian parlor room-type approach to the long-term care insurance puzzle. Canadian Public Policy, $42(2): 262-282$.

Boyer, M. M., De Donder, P., Leroux, M.-L., Fluet, C., and Michaud, P.-C. (2019b). Longterm care risk misperceptions. Geneva Papers on Risk and Insurance - Issues and Practice, 44(2):183-215.

Brown, J., Goda, G., and McGarry, K. (2012). Long-term care insurance demand limited by beliefs about needs, concerns about insurers and care available from family. Health Affairs, 31(6):1294-302.

Brown, J. and Warshawsky, M. (2013). The life care annuity: A new empirical examination of an insurance innovation that addresses problems in the markets for life annuities and long-term care insurance. Journal of Risk and Insurance, 80(3):677-700.

Brown, J. R. and Finkelstein, A. (2008). The Interaction of Public and Private Insurance: Medicaid and the Long-Term Care Insurance Market. American Economic Review, 98(3):10831102 .

Brown, J. R. and Finkelstein, A. (2009). The Private Market for Long-Term Care Insurance in the United States: A Review of the Evidence. Journal of Risk and Insurance, 76(1):5-29.

Courtemanche, C. and He, D. (2009). Tax incentives and the decision to purchase long-term care insurance. Journal of Public Economics, 93(1-2):296-310.

Dardanoni, V. and Li Donni, P. (2016). The welfare cost of unpriced heterogeneity in insurance markets. The RAND Journal of Economics, 47(4):998-1028. 
Davidoff, T. (2009). Housing, health, and annuities. Journal of Risk and Insurance, 76(1):31-52.

Einav, L., Finkelstein, A., and Cullen, M. R. (2010). Estimating Welfare in Insurance Markets Using Variation in Prices. The Quarterly Journal of Economics, 125(3):877-921.

Finkelstein, A., Luttmer, E., and Notowidigdo, M. (2013). What good is health without wealth? the effect of health on the marginal utility of consumption. Journal of the European Economic Association, 11:221-258.

Finkelstein, A. and McGarry, K. (2006). Multiple Dimensions of Private Information: Evidence from the Long-Term Care Insurance Market. American Economic Review, 96(4):938-958.

Friedl, A., de Miranda, K. L., and Schmidt, U. (2014). Insurance demand and social comparison: An experimental analysis. Journal of Risk and Uncertainty, 48(2):97-109.

Genworth (2019). Genworth financial cost of care report. Technical report, Cost of Care Report.

Getzen, T. E. (1988). Longlife insurance: A prototype for funding long-term care. Healthcare Financing Review, 10(2):47-56.

Glenzer, F. and Achou, B. (2019). Annuities, long-term care insurance, and insurer solvency. Geneva Papers on Risk and Insurance - Issues and Practice, 44(2):252-276.

Goda, G. S. (2011). The impact of state tax subsidies for private long-term care insurance on coverage and Medicaid expenditures. Journal of Public Economics, 95(7-8):744-757.

Goldman, D., Shang, B., Hattacharya, J., Garber, A., Hurd, M., Joyce, G., Lakdawalla, D., Panis, C., and Shekelle, P. (2005). Consequences of health trends and medical innovation for the future elderly. Health Affairs, 24(6):W5R5-W5R17.

Hajivassiliou, V. A. and Ruud, P. A. (1994). Chapter 40 Classical estimation methods for LDV models using simulation. In Handbook of Econometrics, volume 4, pages 2383-2441. Elsevier.

Handel, B., Kolstad, J., and Spinnewijn, J. (2019). Information frictions and adverse selection: Policy interventions in health insurance markets. Review of Economics and Statistics, 101(2):326-340.

Handel, B. and Kolstadt, J. (2015). Health insurance for humans: Information frictions, plan choice, and consumer welfare. American Economic Review, 105(8):2449-2500.

Hoy, M., R. Peter, R., and Richter, A. (2014). Take-up for genetic tests and ambiguity. Journal of Risk and Uncertainty, 48(2):111-133.

Hurd, M. D., Michaud, P.-C., and Rohwedder, S. (2017). Distribution of lifetime nursing home use and of out?of?pocket spending. Proceedings of the National Academy of Sciences.

Liu, J. and Liu, W. (2019). The effect of political frictions on long term care insurance. Available at SSRN: https://ssrn.com/abstract=3388542 or http://dx.doi.org/10.2139/ssrn.3388542.

Lockwood, L. M. (2014). Incidental Bequests: Bequest Motives and the Choice to Self-Insure Late-Life Risks. Working Paper 20745, National Bureau of Economic Research.

Louviere, J., Hensher, D., and Swait, J. (2000). Stated Choice Methods, Analysis and Applications. Cambridge University Press. 
Manski, C. F. (1999). Analysis of Choice Expectations in Incomplete Scenarios. Journal of Risk and Uncertainty, 19(1):49-66.

OECD (2011). Help Wanted? - Providing and Paying for Long-Term Care. OECD, oecd press edition.

Pestieau, P. and Ponthiere, G. (2011). The Long Term Care Insurance Puzzle. In Financing Long-Term Care in Europe - Institutions. J. Costa-Font, palgrave macmillan edition.

Pinquart, M. and Sörensen, S. (2002). Older Adults' Preferences for Informal, Formal, and Mixed Support for Future Care Needs: A Comparison of Germany and the United States. The International Journal of Aging and Human Development, 54(4):291-314.

Richter, A., J., S., and H., S. (2014). Health insurance for humans: Information frictions, plan choice, and consumer welfare. Journal of Risk and Uncertainty, 48(85-96):2449-2500.

Spinnewijn, J. (2017). Information frictions and adverse selection: Policy interventions in health insurance markets. American Economic Journal: Economic Policy, 9(1):308-343.

Tennyson, S. and Yang, H. K. (2014). The role of life experience in long-term care insurance decisions. Journal of Economic Psychology, 42:175-188.

Webb, D. C. (2009). Asymmetric information, long-term care insurance, and annuities: The case for bundled contracts. Journal of Risk and Insurance, 76(1):53-85.

Zhou-Richter, T., Browne, M. J., and Gründl, H. (2010). Don`t They Care? Or, Are They Just Unaware? Risk Perception and the Demand for Long-Term Care Insurance. Journal of Risk and Insurance, 77(4):715-747. 


\section{Figures}

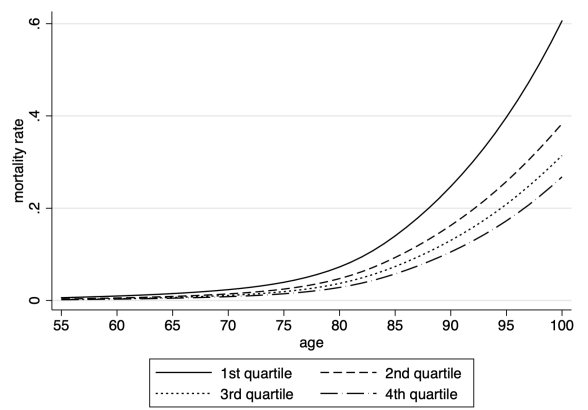

(a) Age 50-54

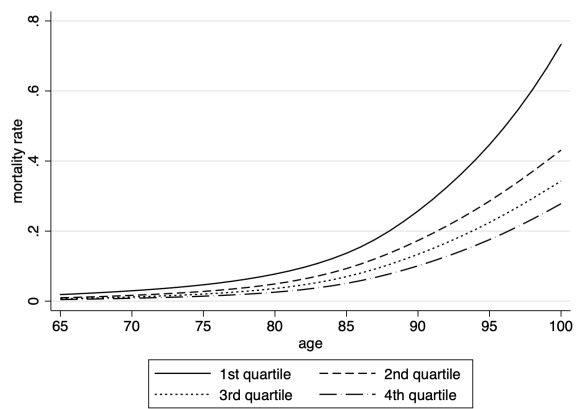

(c) Age 60-64

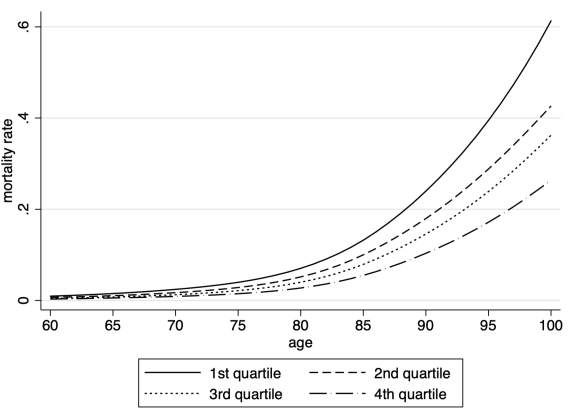

(b) Age 55-59

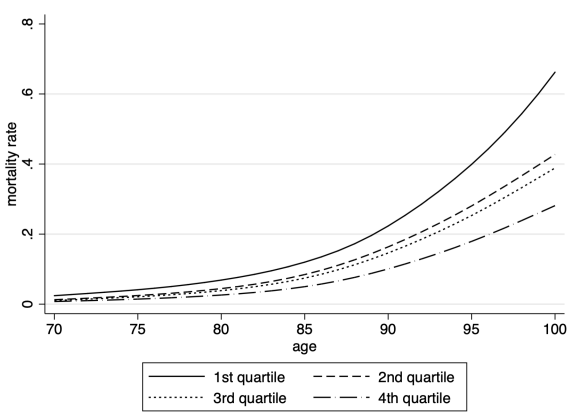

(d) Age 65-69

Figure 1: Mortality Risk Projections by Age Group: For each age group, we sort respondents by projected remaining life expectancy and plot average mortality rates by quartiles. 


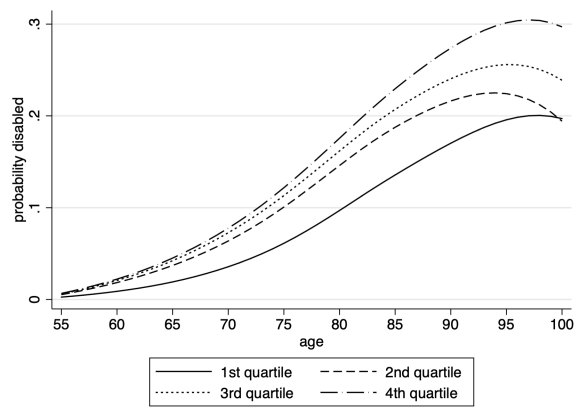

(a) Age 50-54

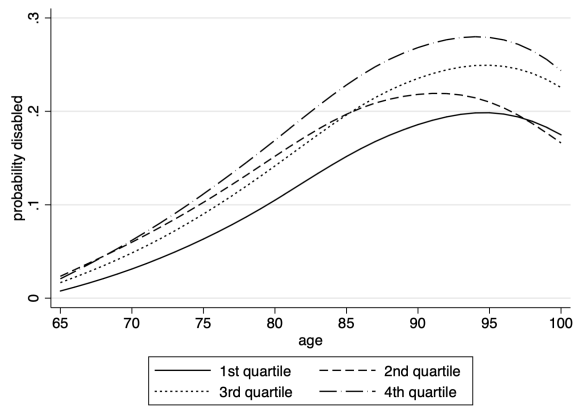

(c) Age 60-64

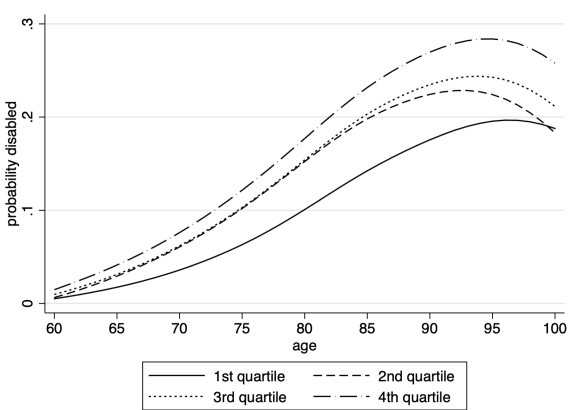

(b) Age 55-59

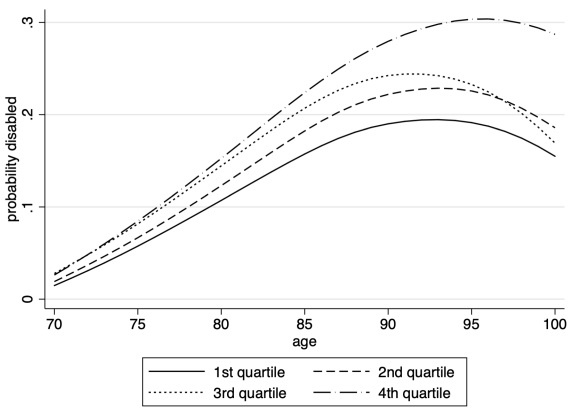

(d) Age 65-69

Figure 2: Disability Risk Projections by Age Group: For each age group, we sort respondents by projected expected number of years with disability and plot average disability rates by quartiles. These disability rates are conditional on survival at each age. 


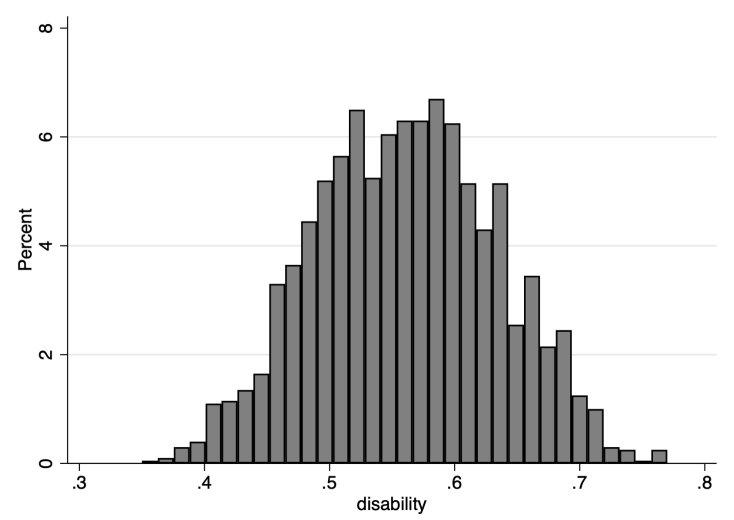

(a) Lifetime Disability

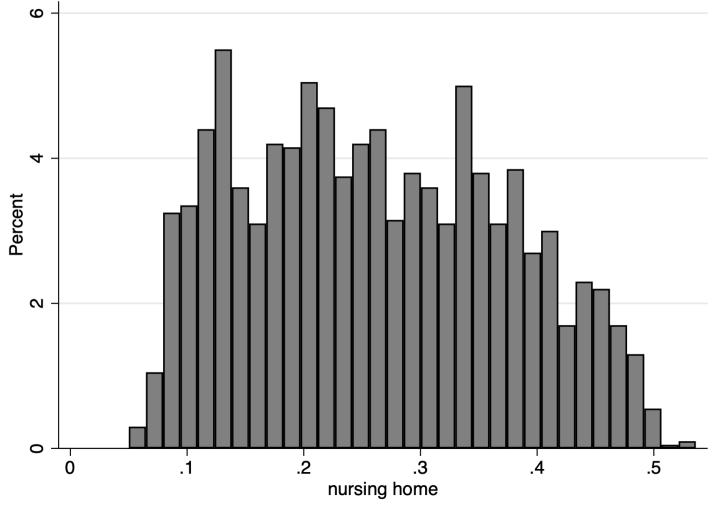

(b) Lifetime Nursing Home

Figure 3: Probability of Ever Being Disabled or Enter a Nursing Home: The distribution of these risks are computed from COMPAS. 


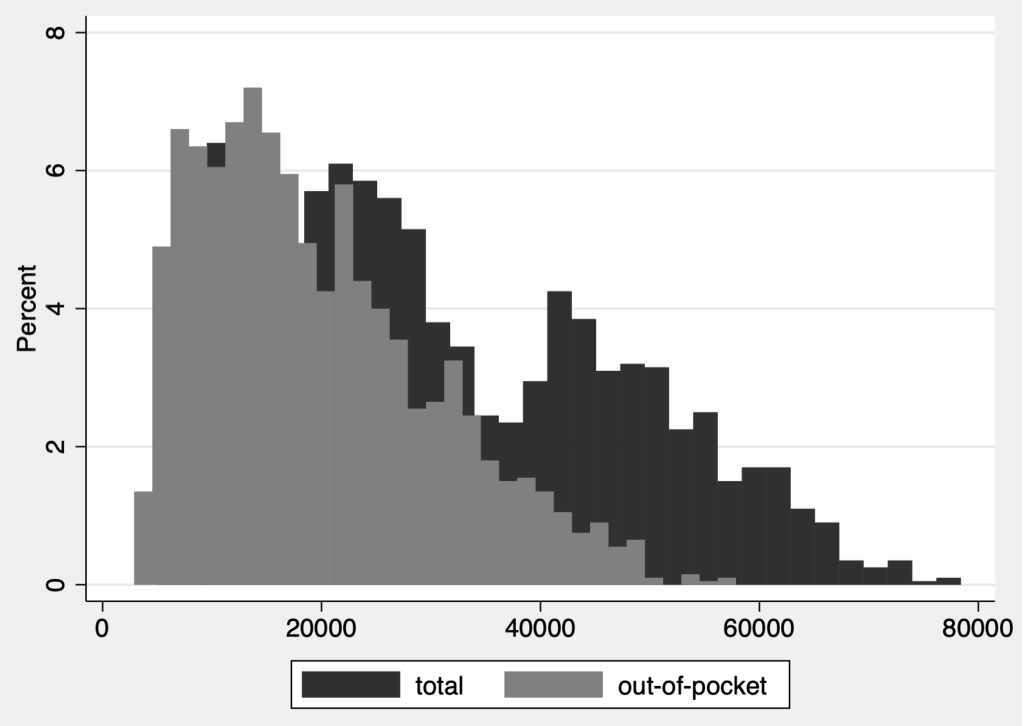

Figure 4: Expected Present Value of Cost to Respondents: A discount rate of $3 \%$ is used. 


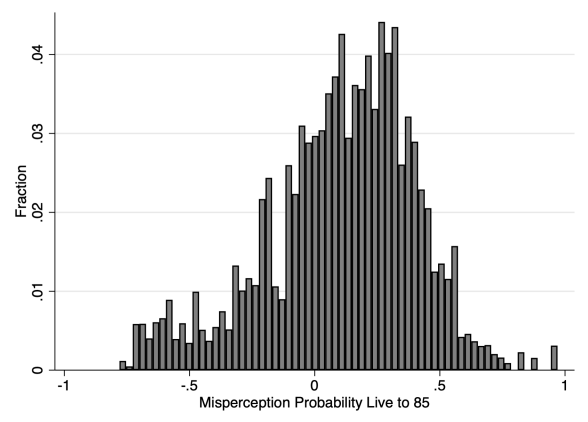

(a) Probability Live to Age 85

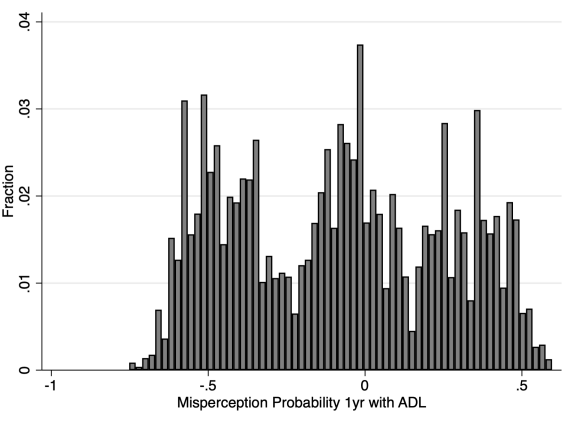

(b) Lifetime $1 y r+$ ADL

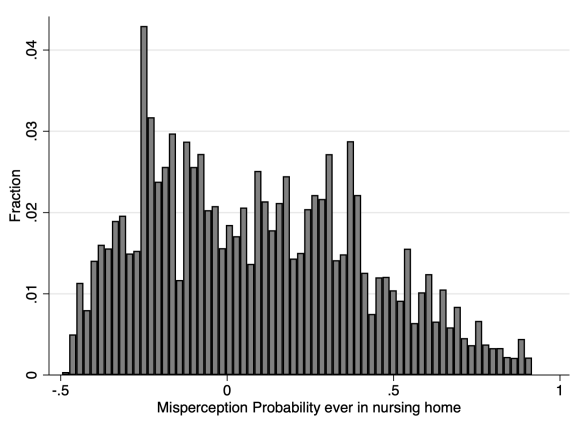

(c) Lifetime Nursing Home

Figure 5: Difference between subjective and objective risk (misperception) for survival, disability and nursing home risks. A positive (negative) number implies the respondent overestimates (underestimates) the risk. 


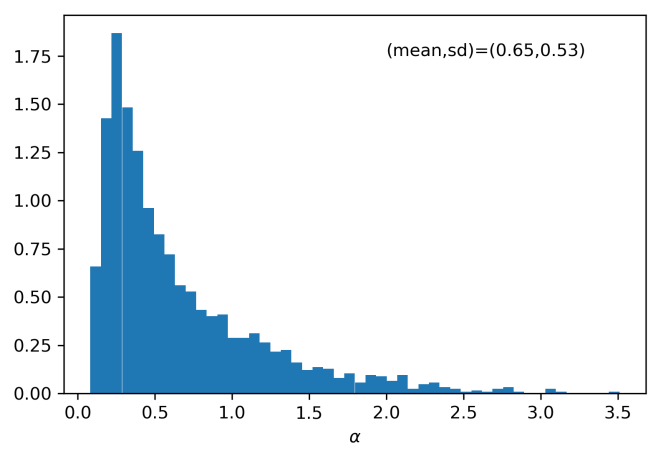

(a) With Frictions

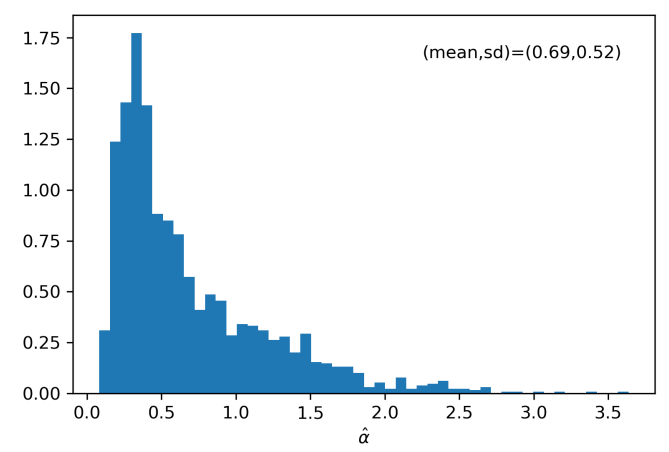

(b) No Frictions

Figure 6: Distribution of Elasticity Estimates from Demand Model: Estimates of $\alpha$ and $\hat{\alpha}$ in elasticity form using the demand model (equation 1). These estimates are obtained for the baseline contract with a $2000 \$$ LTCI benefit and no life insurance benefit. 

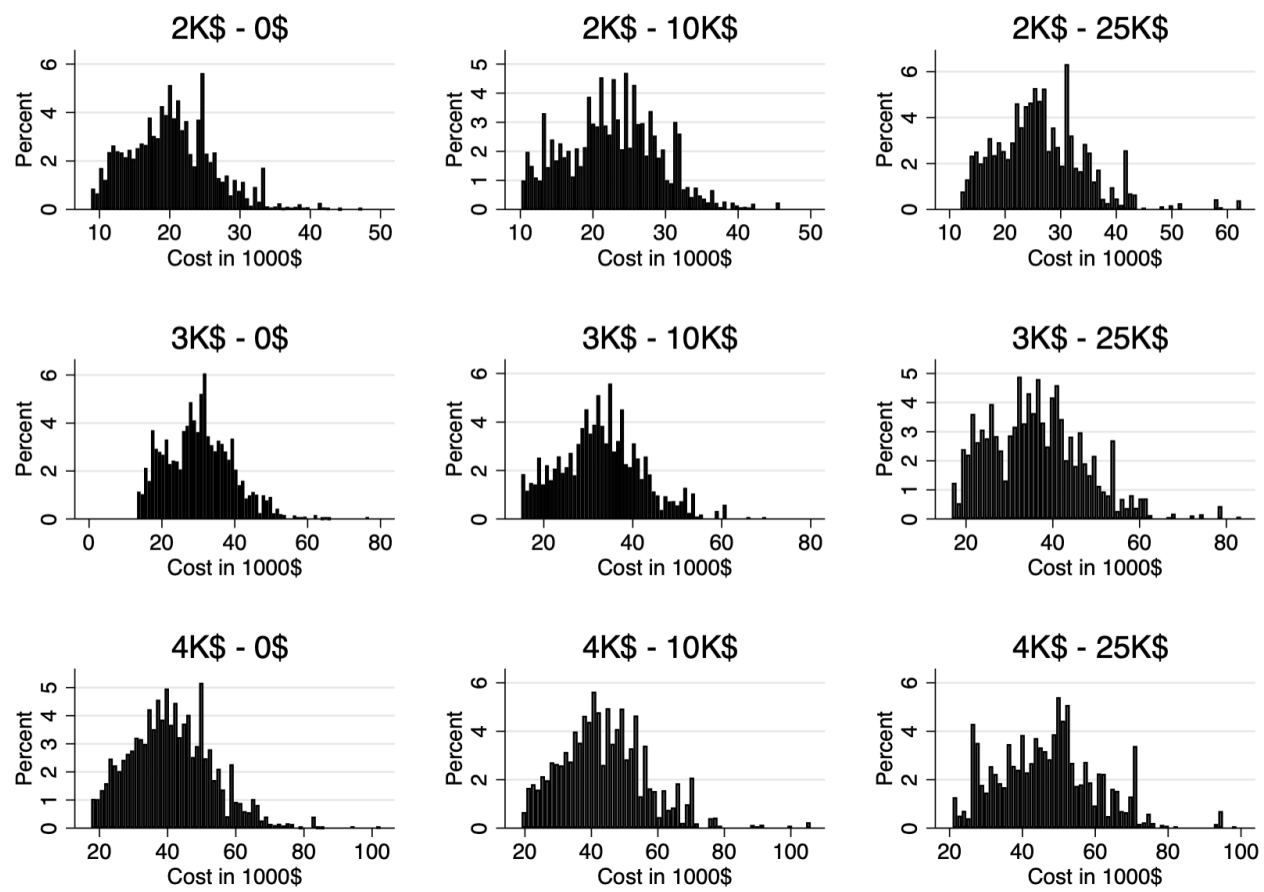

Figure 7: Distribution of Expected Cost by Contract: In each panel, we report a histogram of the distribution of expected costs, as defined in the paper, for each contract defined by the LTC benefit and the life insurance benefit. 

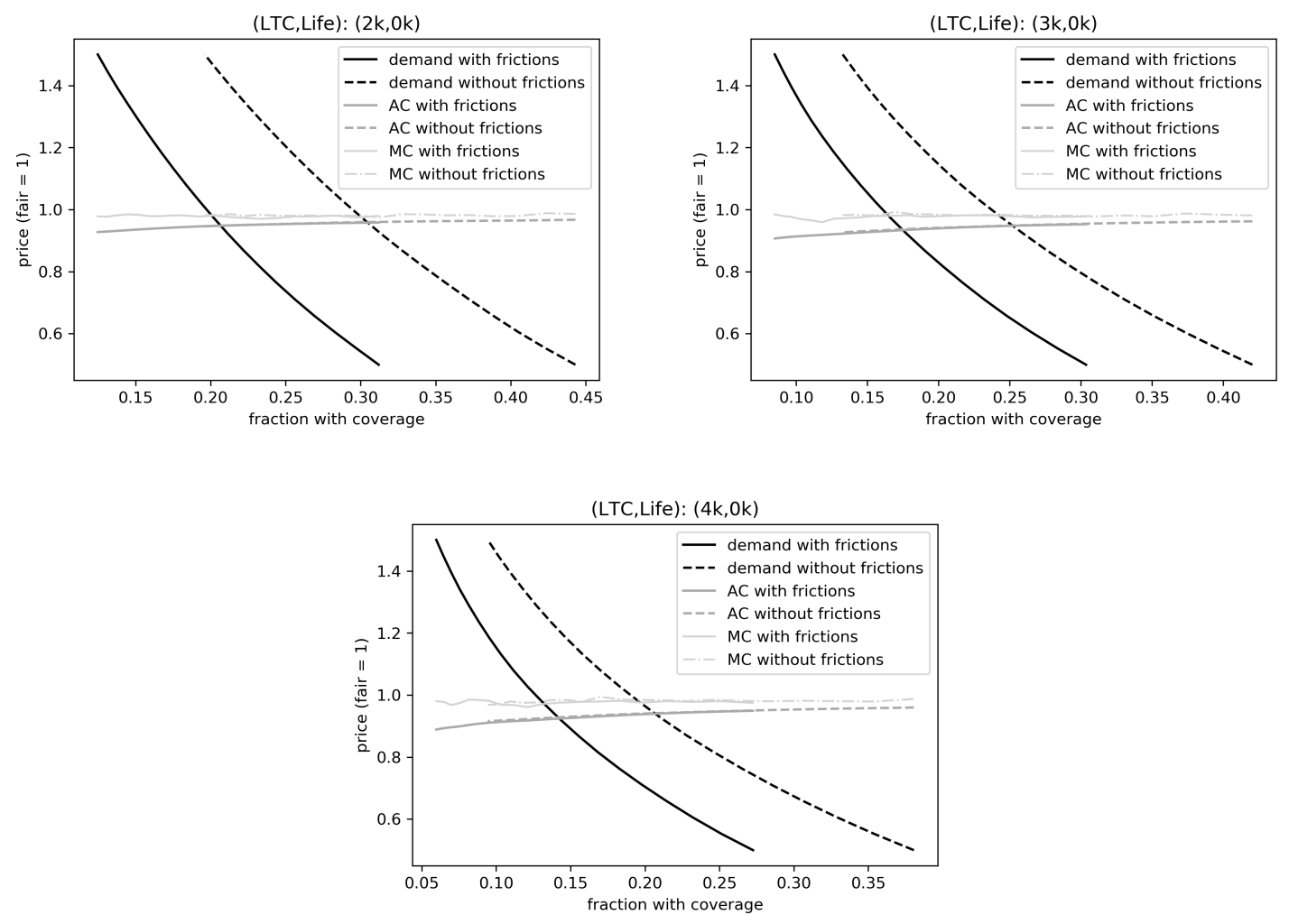

Figure 8: Market Equilibrium for Contracts without Life insurance benefits: For each contract, we compute the competitive equilibrium with and without frictions. We plot demand as well as average cost and marginal cost curves. 

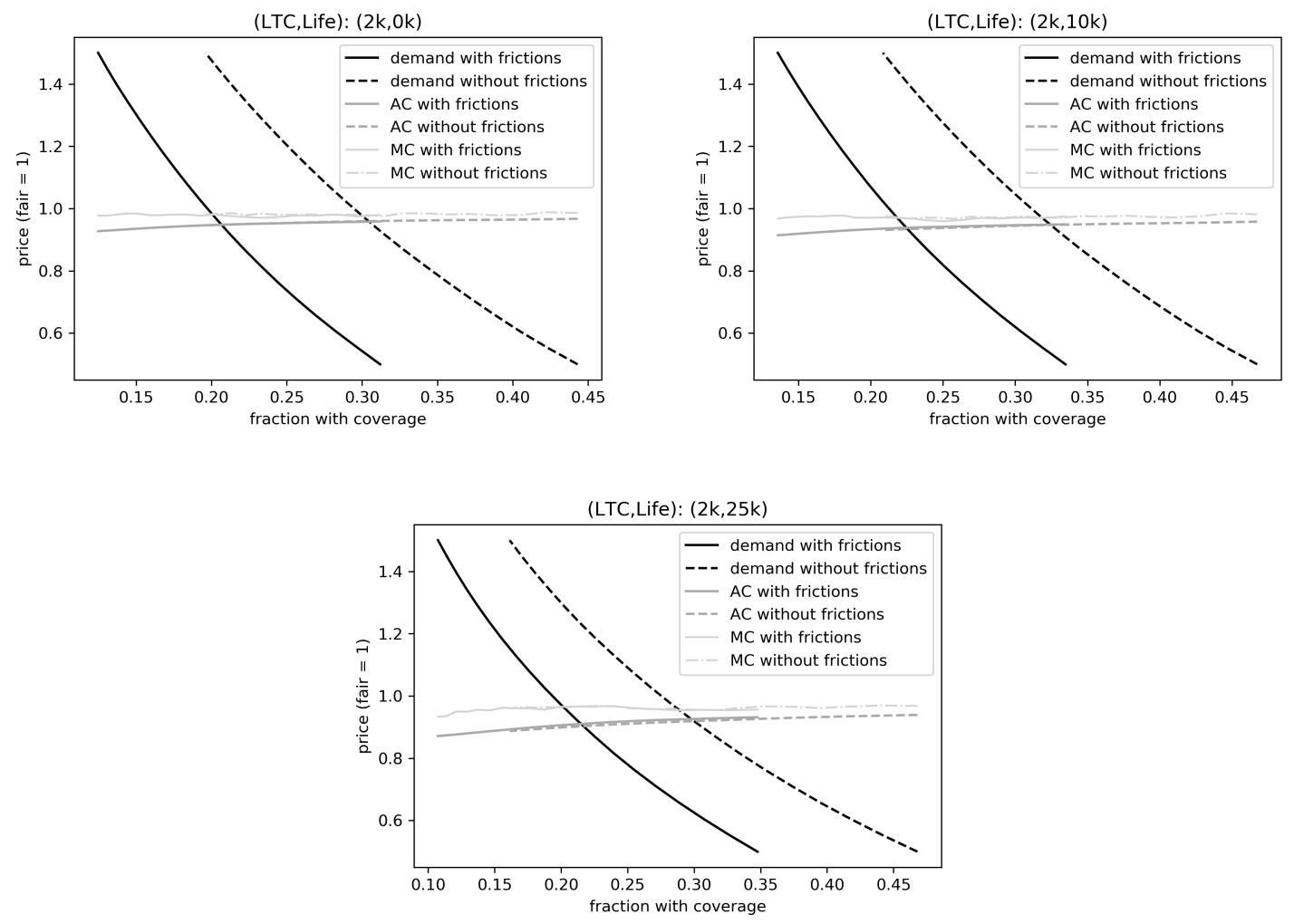

Figure 9: Market Equilibrium for Contracts with Varying Life Insurance Benefit: For each contract, we compute the competitive equilibrium with and without frictions. We plot demand as well as average cost and marginal cost curves. 


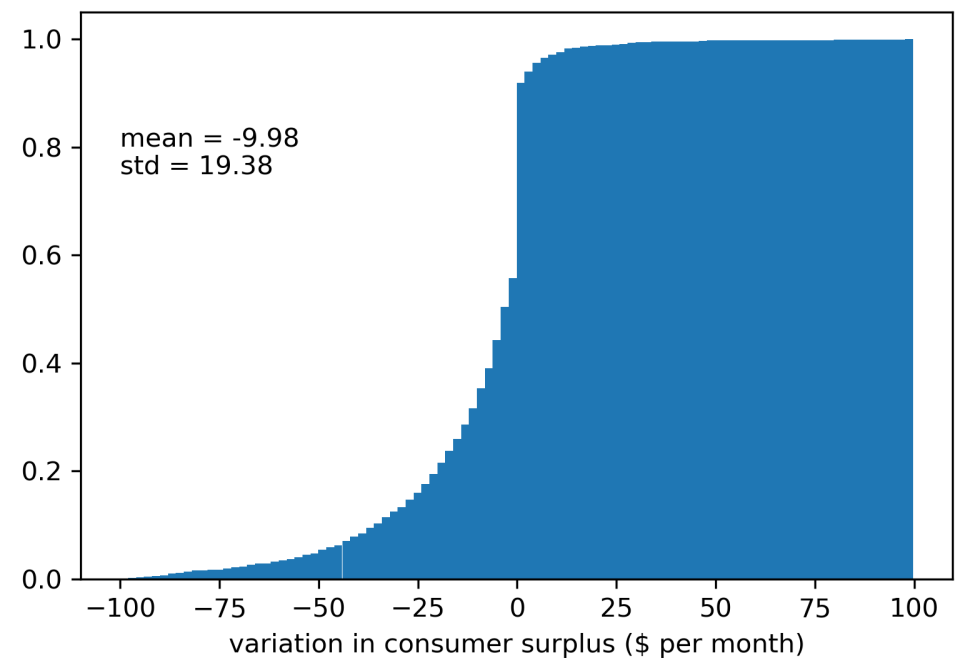

Figure 10: Variation of Consumer Surplus between Competitive Equilibrium with Frictions and Social Optimum: For the contract with a LTCI benefit of $\$ 2,000$ and no life insurance benefit, we report for each respondent, the welfare (consumer surplus) at the competitive equilibrium minus the welfare at the social optimum. The cumulative distribution function is plotted over discrete intervals. 


\section{Tables}

\begin{tabular}{lrrr}
\hline \hline Age & & Female & Male \\
$50-54$ & Model & 139 & 119 \\
& Data & 130 & 97 \\
$55-59$ & Model & 183 & 155 \\
& Data & 175 & 123 \\
60-64 & Model & 220 & 194 \\
& Data & 238 & 174 \\
$65-69$ & Model & 291 & 263 \\
& Data & 352 & 262 \\
\hline \hline
\end{tabular}

Table 1: Monthly Premiums from data (CAA Quebec with a 2\% inflation guarantee) and Actuarial Premiums from modelling (COMPAS microsimulation model). Sample average for $\$ 2,000$ and $\$ 3,000$ per month benefit. 


\begin{tabular}{|c|c|c|c|}
\hline No LTCI & & LTCI & \\
\hline Fraction (\%) & 89.48 & Fraction (\%) & 10.52 \\
\hline Knowledge of LTCI (\%) & & Knowledge of LTCI (\%) & \\
\hline A lot & 6.90 & A lot & 29.60 \\
\hline A little & 53.27 & A little & 64.94 \\
\hline None at all & 39.82 & None at all & 5.46 \\
\hline Why don't you have LTCI? (\%) & & How did you come to purchase LTCI? (\%) & \\
\hline Never offered one & 44.1 & Offered & 53.43 \\
\hline Not yet made decision & 7.77 & Searched myself & 9.19 \\
\hline Used to have one & 0.5 & Other & 37.38 \\
\hline Too expensive & 18.97 & & \\
\hline Doesn't cover my needs & 2.25 & LTC policy & \\
\hline Don't need such a policy & 13.97 & Premium & $\$ 115.8$ \\
\hline Don't know what it is & 7.93 & Benefit & $\$ 2,467$ \\
\hline Other & 4.19 & & \\
\hline Do you have life insurance? (\%) & & Do you have life insurance? (\%) & \\
\hline Yes & 68.10 & Yes & 75.88 \\
\hline No & 31.07 & No & 21.34 \\
\hline Don't know & 0.83 & Don't know & 2.78 \\
\hline
\end{tabular}

Table 2: Holding of Long-Term Care and Life Insurance: $N=1819$ respondents with non-missing response to whether or not has Long-term care insurance. 


\begin{tabular}{rrr}
\hline \hline & & \\
Number of $0 \%$ choice & $\%$ & Cumulative \\
\hline 0 & 36.55 & 36.55 \\
1 & 13.64 & 50.19 \\
2 & 9.38 & 59.57 \\
3 & 8.79 & 68.37 \\
4 & 8.01 & 76.38 \\
5 & 23.62 & 100 \\
\hline \hline
\end{tabular}

Table 3: Distribution of agents by number of $0 \%$-probability choice to buy LTCI over the 5 scenarios presented. 


\begin{tabular}{lrrrrr}
\hline \hline & \multicolumn{5}{c}{ Life benefit } \\
LTC benefit & 0 & 10000 & 25000 & Total \\
\hline & & & & & \\
2000 & .2713 & .3128 & .3328 & .292 \\
3000 & .2491 & .2855 & .2858 & .2639 \\
& 4000 & .2044 & .2669 & .2559 & .2273 \\
Total & & & & & \\
\hline \hline
\end{tabular}

Table 4: Mean choice probability by combination of LTC and Life benefit in scenarios. 


\begin{tabular}{|c|c|c|c|c|c|}
\hline & \multicolumn{2}{|c|}{ Price: $\alpha(\cdot)$} & \multicolumn{2}{|c|}{ Intercept: $\mu(\cdot)$} & \multirow{2}{*}{$\begin{array}{c}\text { Marginal effect } \\
\text { estimate }\end{array}$} \\
\hline & estimate & se & estimate & se & \\
\hline Shifters & \multicolumn{2}{|c|}{$\psi$} & \multicolumn{2}{|c|}{$\beta$} & \\
\hline $55-59$ men & -0.5294 & 0.1300 & -0.0726 & 0.044 & 0.0585 \\
\hline 60-64 men & 0.0309 & 0.1016 & 0.0595 & 0.042 & 0.0265 \\
\hline 65-69 men & -0.1712 & 0.0972 & 0.0498 & 0.040 & 0.0586 \\
\hline 50-54 female & -0.4302 & 0.1242 & 0.0243 & 0.051 & 0.0926 \\
\hline 55-59 female & -0.3172 & 0.1108 & 0.1013 & 0.046 & 0.1133 \\
\hline $60-64$ female & -0.7143 & 0.1512 & 0.0131 & 0.064 & 0.1389 \\
\hline 65-69 female & -0.1934 & 0.1345 & 0.0913 & 0.057 & 0.0851 \\
\hline quebec & 0.1922 & 0.0511 & 0.0282 & 0.023 & -0.0202 \\
\hline college & -0.1197 & 0.0541 & -0.0386 & 0.024 & 0.0012 \\
\hline married & -0.0485 & 0.0522 & 0.0163 & 0.025 & 0.0178 \\
\hline n kids & -0.0140 & 0.0171 & -0.0141 & 0.008 & -0.0051 \\
\hline savings & -0.3522 & 0.1038 & -0.0147 & 0.044 & 0.0571 \\
\hline hh income & -0.0851 & 0.0416 & -0.0038 & 0.016 & 0.0137 \\
\hline$e_{s, x}$ & 0.0022 & 0.0082 & 0.0035 & 0.003 & 0.0015 \\
\hline$e_{d, x}$ & -0.1932 & 0.0541 & -0.0435 & 0.024 & 0.0121 \\
\hline own home & 0.1157 & 0.0574 & -0.0919 & 0.027 & -0.0711 \\
\hline bequest motive & -0.2554 & 0.0589 & -0.0043 & 0.024 & 0.0448 \\
\hline risk averse & -0.2728 & 0.0617 & -0.0233 & 0.026 & 0.0378 \\
\hline family & -0.1884 & 0.0484 & -0.0484 & 0.021 & 0.0086 \\
\hline pref formal care & -0.0332 & 0.0473 & 0.0435 & 0.021 & 0.0297 \\
\hline pr family cares & 0.1065 & 0.0695 & 0.0990 & 0.033 & 0.0339 \\
\hline pr family cares dnk & -0.2569 & 0.0755 & -0.0764 & 0.034 & 0.0061 \\
\hline bias survival & -0.3253 & 0.0920 & -0.0319 & 0.041 & 0.0428 \\
\hline bias survival dnk & -0.0178 & 0.0758 & -0.0581 & 0.031 & -0.0281 \\
\hline bias disability & -0.2686 & 0.0902 & -0.0216 & 0.041 & 0.0379 \\
\hline bias disability dnk & -0.0445 & 0.0595 & -0.0661 & 0.027 & -0.0275 \\
\hline bias NH & -0.2625 & 0.0954 & 0.1081 & 0.041 & 0.1070 \\
\hline bias NH dnk & 0.0864 & 0.0643 & 0.0350 & 0.030 & 0.0030 \\
\hline no crowdout & -0.1901 & 0.0535 & -0.1355 & 0.027 & -0.0382 \\
\hline bias NH cost & -0.0257 & 0.0193 & -0.0147 & 0.008 & -0.0032 \\
\hline dnk NH costs & -0.1925 & 0.0756 & -0.1294 & 0.034 & -0.0345 \\
\hline thinks $\mathrm{NH}$ free & -0.0428 & 0.0886 & -0.0285 & 0.039 & -0.0075 \\
\hline wait time $\mathrm{NH}$ & 0.0029 & 0.0035 & 0.0023 & 0.002 & 0.0007 \\
\hline dnk $\mathrm{NH}$ wait time & 0.2040 & 0.0680 & 0.1345 & 0.030 & 0.0351 \\
\hline knows little LTCI & 0.2989 & 0.0763 & -0.0378 & 0.034 & -0.0756 \\
\hline knows nothing LTCI & -0.0167 & 0.0689 & -0.0696 & 0.031 & -0.0346 \\
\hline intercept & -4.8856 & 0.2883 & 0.8074 & 0.129 & \\
\hline Contract, ref $(2 \mathrm{k}, 0)$ & \multicolumn{2}{|c|}{$\delta$} & \multicolumn{2}{|c|}{$\gamma$} & \\
\hline$(2 \mathrm{k}, 10 \mathrm{k})$ & -0.0938 & 0.0678 & 0.0370 & 0.0249 & 0.0373 \\
\hline$(2 \mathrm{k}, 25 \mathrm{k})$ & 0.1468 & 0.0620 & 0.1517 & 0.0264 & 0.0550 \\
\hline$(3 \mathrm{k}, 0 \mathrm{k})$ & 0.0413 & 0.0476 & 0.0926 & 0.0202 & 0.0425 \\
\hline$(3 \mathrm{k}, 10 \mathrm{k})$ & 0.0387 & 0.0712 & 0.1546 & 0.0299 & 0.0765 \\
\hline$(3 \mathrm{k}, 25 \mathrm{k})$ & -0.0432 & 0.0620 & 0.1468 & 0.0287 & 0.0874 \\
\hline$(4 \mathrm{k}, 0 \mathrm{k})$ & -0.0461 & 0.0492 & 0.1068 & 0.0227 & 0.0663 \\
\hline$(4 \mathrm{k}, 10 \mathrm{k})$ & -0.0841 & 0.0644 & 0.1746 & 0.0309 & 0.1100 \\
\hline$(4 \mathrm{k}, 25 \mathrm{k})$ & -0.0144 & 0.0567 & 0.2218 & 0.0293 & 0.1226 \\
\hline \multirow[t]{2}{*}{ heterogeneity } & \multicolumn{2}{|c|}{$\sigma_{\eta}$} & \multicolumn{2}{|c|}{$\sigma_{\nu}$} & \\
\hline & 0.8087 & 0.0254 & 0.2919 & 0.0075 & \\
\hline $\log L$ & -3058.8 & & & & \\
\hline
\end{tabular}

Table 5: Demand Model Estimates: Estimates by maximum simulated likelihood with 50 draws. $e_{s, x}$ refers to remaining life expectancy at age $x$ and $e_{d, x}$ refers to expected number of years with $2+$ ADL. Marginal effects are average partial effects of characteristics on the (censored) probability of purchase evaluated for the first contract (in the case of $x$ ) and for each contract ( $z$ ). The average premium faced by respondents across scenarios is used to compute this marginal effect. 


\begin{tabular}{lcccccc}
\hline & Equi (frictions) & Equi (no frictions) & Optimum & AS Loss & Frictions Loss & Total Loss \\
\hline$(2 \mathrm{k}, 0 \mathrm{k})$ & {$[0.948,0.207]$} & {$[0.96,0.304]$} & {$[0.978,0.3]$} & -0.00012 & -0.18051 & -0.18063 \\
$(2 \mathrm{k}, 10 \mathrm{k})$ & {$[0.939,0.225]$} & {$[0.947,0.324]$} & {$[0.972,0.318]$} & -0.00025 & -0.17329 & -0.17354 \\
$(2 \mathrm{k}, 25 \mathrm{k})$ & {$[0.91,0.215]$} & {$[0.919,0.3]$} & {$[0.963,0.286]$} & -0.00115 & -0.16983 & -0.17098 \\
$(3 \mathrm{k}, 0 \mathrm{k})$ & {$[0.934,0.175]$} & {$[0.949,0.252]$} & {$[0.983,0.242]$} & -0.00076 & -0.18605 & -0.18681 \\
$(3 \mathrm{k}, 10 \mathrm{k})$ & {$[0.924,0.191]$} & {$[0.938,0.268]$} & {$[0.978,0.255]$} & -0.00122 & -0.17834 & -0.17956 \\
$(3 \mathrm{k}, 25 \mathrm{k})$ & {$[0.911,0.183]$} & {$[0.923,0.258]$} & {$[0.973,0.243]$} & -0.00188 & -0.17856 & -0.18045 \\
$(4 \mathrm{k}, 0 \mathrm{k})$ & {$[0.924,0.142]$} & {$[0.941,0.206]$} & {$[0.982,0.195]$} & -0.00169 & -0.19781 & -0.19951 \\
$(4 \mathrm{k}, 10 \mathrm{k})$ & {$[0.92,0.17]$} & {$[0.934,0.237]$} & {$[0.977,0.224]$} & -0.00174 & -0.18492 & -0.18666 \\
$(4 \mathrm{k}, 25 \mathrm{k})$ & {$[0.902,0.159]$} & {$[0.917,0.22]$} & {$[0.974,0.202]$} & -0.00449 & -0.18627 & -0.19076 \\
\hline
\end{tabular}

Table 6: Equilibrium and Welfare Computations: For each contract, we provide the equilibrium with and without frictions, the optimum (relative price, fraction insured) and the welfare loss due to asymmetric information, frictions (and total). These welfare losses are expressed in relative terms (relative to the optimum). 


\begin{tabular}{lcccrrr}
\hline & Equi (frictions) & Equi (no frictions) & Optimum & AS Loss & Frictions Loss & Total Loss \\
\hline $50-54$ men & {$[0.933,0.242]$} & {$[0.942,0.341]$} & {$[0.969,0.334]$} & -0.00021 & -0.16004 & -0.16026 \\
$55-59$ men & {$[1.007,0.23]$} & {$[1.019,0.365]$} & {$[1.026,0.363]$} & -0 & -0.16112 & -0.16112 \\
$60-64$ men & {$[0.998,0.215]$} & {$[1.012,0.295]$} & {$[0.983,0.303]$} & -0.00025 & -0.19122 & -0.19147 \\
$65-69$ men & {$[0.973,0.198]$} & {$[0.99,0.297]$} & {$[0.977,0.301]$} & $-4 \mathrm{e}-05$ & -0.15595 & -0.156 \\
$50-54$ female & {$[0.884,0.18]$} & {$[0.899,0.256]$} & {$[0.906,0.254]$} & $-3 \mathrm{e}-05$ & -0.20768 & -0.20771 \\
$55-59$ female & {$[1.014,0.174]$} & {$[1.007,0.286]$} & {$[1.01,0.285]$} & -0 & -0.24337 & -0.24337 \\
$60-64$ female & {$[0.919,0.217]$} & {$[0.922,0.305]$} & {$[0.95,0.297]$} & -0.00027 & -0.18395 & -0.18422 \\
$65-69$ female & {$[1.022,0.16]$} & {$[1.037,0.24]$} & {$[1.008,0.247]$} & -0.00058 & -0.2112 & -0.21178 \\
\hline
\end{tabular}

Table 7: Segmented Equilibrium and Welfare Computations: For the contract offering a $\$ 2,000$ LTCI benefit and no life insurance, we compute the equilibrium and optimum by risk segmentation groups (age and sex). 


\begin{tabular}{llrrrrrr}
\hline & Q equilibrium & Q no frictions & Q optimum & AS Loss & Frictions Loss & Total Loss \\
\hline$(2 \mathrm{k}, 0 \mathrm{k})$ & Segmented & 0.2005 & 0.2953 & 0.2954 & -0.0002 & -0.1854 & -0.1855 \\
& Uniform & 0.2070 & 0.3040 & 0.3000 & -0.0001 & -0.1805 & -0.1806 \\
$(2 \mathrm{k}, 10 \mathrm{k})$ & Segmented & 0.2170 & 0.3135 & 0.3126 & -0.0001 & -0.1789 & -0.1790 \\
& Uniform & 0.2250 & 0.3240 & 0.3180 & -0.0002 & -0.1733 & -0.1735 \\
$(2 \mathrm{k}, 25 \mathrm{k})$ & Segmented & 0.1995 & 0.2788 & 0.2765 & -0.0008 & -0.1800 & -0.1808 \\
& Uniform & 0.2150 & 0.3000 & 0.2860 & -0.0012 & -0.1698 & -0.1710 \\
$(3 \mathrm{k}, 0 \mathrm{k})$ & Segmented & 0.1634 & 0.2364 & 0.2363 & -0.0010 & -0.1950 & -0.1960 \\
& Uniform & 0.1750 & 0.2520 & 0.2420 & -0.0008 & -0.1860 & -0.1868 \\
$(3 \mathrm{k}, 10 \mathrm{k})$ & Segmented & 0.1773 & 0.2493 & 0.2485 & -0.0010 & -0.1878 & -0.1888 \\
& Uniform & 0.1910 & 0.2680 & 0.2550 & -0.0012 & -0.1783 & -0.1796 \\
$(3 \mathrm{k}, 25 \mathrm{k})$ & Segmented & 0.1672 & 0.2368 & 0.2333 & -0.0014 & -0.1906 & -0.1920 \\
& Uniform & 0.1830 & 0.2580 & 0.2430 & -0.0019 & -0.1786 & -0.1804 \\
$(4 \mathrm{k}, 0 \mathrm{k})$ & Segmented & 0.1290 & 0.1890 & 0.1894 & -0.0013 & -0.2103 & -0.2116 \\
& Uniform & 0.1420 & 0.2060 & 0.1950 & -0.0017 & -0.1978 & -0.1995 \\
$(4 \mathrm{k}, 10 \mathrm{k})$ & Segmented & 0.1542 & 0.2170 & 0.2165 & -0.0015 & -0.1966 & -0.1982 \\
& Uniform & 0.1700 & 0.2370 & 0.2240 & -0.0017 & -0.1849 & -0.1867 \\
$(4 \mathrm{k}, 25 \mathrm{k})$ & Segmented & 0.1397 & 0.1950 & 0.1915 & -0.0021 & -0.2014 & -0.2035 \\
& Uniform & 0.1590 & 0.2200 & 0.2020 & -0.0045 & -0.1863 & -0.1908 \\
\hline
\end{tabular}

Table 8: Segmented Equilibrium and Welfare Computations: For each contract, we compare the results with segmentation by risk class $\left(\tau_{h}\right)$ and those without (uniform $\tau$ ). 


\begin{tabular}{|c|c|c|c|c|c|c|c|c|c|}
\hline & \multirow[b]{2}{*}{ Q frictions } & \multicolumn{4}{|c|}{ Q no frictions } & \multicolumn{4}{|c|}{ Welfare variations } \\
\hline & & Perceptions & Knowledge & Awareness & Total & Perceptions & Knowledge & Awareness & Tota \\
\hline$(2 \mathrm{k}, 0 \mathrm{k})$ & 0.207 & 0.208 & 0.248 & 0.256 & 0.304 & 0.0066 & -0.0582 & -0.1289 & -0.1806 \\
\hline$(2 \mathrm{k}, 10 \mathrm{k})$ & 0.225 & 0.227 & 0.266 & 0.277 & 0.324 & 0.0068 & -0.0648 & -0.1152 & -0.1735 \\
\hline$(2 \mathrm{k}, 25 \mathrm{k})$ & 0.215 & 0.215 & 0.244 & 0.267 & 0.300 & 0.0027 & -0.1127 & -0.0599 & -0.1710 \\
\hline$(3 \mathrm{k}, 0 \mathrm{k})$ & 0.175 & 0.174 & 0.201 & 0.222 & 0.252 & -0.0016 & -0.1117 & -0.0727 & -0.1868 \\
\hline$(3 \mathrm{k}, 10 \mathrm{k})$ & 0.191 & 0.190 & 0.216 & 0.240 & 0.268 & -0.0023 & -0.1281 & -0.0479 & -0.1796 \\
\hline$(3 \mathrm{k}, 25 \mathrm{k})$ & 0.183 & 0.183 & 0.207 & 0.231 & 0.258 & -0.0002 & -0.1265 & -0.0518 & -0.1804 \\
\hline$(4 \mathrm{k}, 0 \mathrm{k})$ & 0.142 & 0.141 & 0.162 & 0.185 & 0.206 & -0.0053 & -0.1385 & -0.0539 & -0.1995 \\
\hline$(4 \mathrm{k}, 10 \mathrm{k})$ & 0.170 & 0.168 & 0.189 & 0.216 & 0.237 & -0.0061 & -0.1493 & -0.0295 & -0.1867 \\
\hline$(4 \mathrm{k}, 25 \mathrm{k})$ & 0.159 & 0.158 & 0.174 & 0.204 & 0.220 & -0.0055 & -0.1771 & -0.0037 & -0.1908 \\
\hline
\end{tabular}

Table 9: Decomposition of Frictions: We compare the equilibrium quantity and welfare variation in scenarios which implement one friction at a time (risk perceptions, knowledge, awareness). 


\section{A Lapsing}

We use data from the Long Term Care Intercompany Experience Study 2000-2011 from the Society of Actuaries to compute annual lapsing probabilities. This study gathers information on lapsing from 22 insurance companies. Lapsing can occur due to death or other reasons. Given the definition we use in the paper, we want the probability of lapsing conditional on survival. We use definition 2 of voluntary lapsing, which excludes companies where more than $25 \%$ of terminations were of unknown cause. In the table below we report estimates of the lapsing probability by age and gender. Because there is no clear pattern with age and differences by gender are small, we use a uniform probability of lapsing of $1.8 \%$.

\begin{tabular}{lrr}
\hline \hline Age & Females & Males \\
\hline$<50$ & 0.056 & 0.070 \\
$50-59$ & 0.023 & 0.025 \\
$60-69$ & 0.013 & 0.015 \\
$70-79$ & 0.011 & 0.011 \\
$80+$ & 0.027 & 0.022 \\
\hline Total & 0,018 & 0,018 \\
\hline \hline
\end{tabular}

Table A.1: Lapsing probabilities by age and gender. Source: Society of Actuaries Long-Term Care Intercompany Experience Study 


\section{B Demand Estimation}

The model presented in equations 1,2 and 3 has a number of parameters to estimate which we can collect in a vector $\theta=\left(\beta, \gamma, \delta, \psi, \sigma_{\nu}, \sigma_{\eta}, \sigma_{\epsilon}\right)$. For ease of notation, define $\mathbf{X}_{i, t}=\left(\mathbf{x}_{i}, \mathbf{z}_{i, t}, p_{i, t}\right)$. Let $I_{q_{i, t}>0}$ be a dummy variable indicating whether demand is positive (1) or zero (0). Also let the index be denoted by

$$
\pi\left(\mathbf{X}_{i, t}, \nu_{i}, \eta_{i}\right)=-\alpha\left(\mathbf{x}_{i}, \mathbf{z}_{i, t}, \eta_{i}\right) p_{i, t}+\mu\left(\mathbf{x}_{i}, \mathbf{z}_{i, t}, \nu_{i}\right)
$$

The probability of observing one particular $q_{i, t}$ conditional on $\mathbf{X}_{i, t}$ and $\eta_{i}, \nu_{i}$ is given by:

$\operatorname{Pr}\left(q_{i, t} \mid \mathbf{X}_{i, t}, \eta_{i}, \nu_{i}\right)=\left(\frac{1}{\sigma_{\epsilon}} \phi\left(\frac{q_{i, t}-\pi\left(\mathbf{X}_{i, t}, \nu_{i}, \eta_{i}\right)}{\sigma_{\epsilon}}\right)\right)^{I_{q_{i, t}>0}}\left(1-\Phi\left(\frac{\pi\left(\mathbf{X}_{i, t}, \nu_{i}, \eta_{i}\right)}{\sigma_{\epsilon}}\right)\right)^{1-I_{q_{i, t}>0}}$

where $\phi(\cdot)$ is the standard normal pdf (density) and $\Phi(\cdot)$ is the standard normal cdf (cumulative distribution function).

Because the $\epsilon_{i, t}$ are independent, we have that

$$
\operatorname{Pr}\left(\mathbf{q}_{i} \mid \mathbf{X}_{i}, \eta_{i}, \nu_{i}\right)=\prod_{t=1}^{T} \operatorname{Pr}\left(q_{i, t} \mid \mathbf{X}_{i, t}, \eta_{i}, \nu_{i}\right)
$$

where $\mathbf{q}_{i}=\left(q_{i, 1}, \ldots q_{i, T}\right)^{\prime}$ and $X_{i}=\left(X_{i, 1}, \ldots, X_{i, T}\right)^{\prime}$.

Since $\nu_{i} \sim N\left(0, \sigma_{\nu}^{2}\right)$ and $\eta_{i} \sim N\left(0, \sigma_{\eta}^{2}\right)$, an unbiased simulator of the probability $\operatorname{Pr}\left(\mathbf{q}_{i} \mid \mathbf{X}_{i}\right)=$ $\mathbf{E}_{\left(\eta_{i}, \nu_{i}\right)} \operatorname{Pr}\left(\mathbf{q}_{i} \mid \mathbf{X}_{i}, \eta_{i}, \nu_{i}\right)$ is given by

$$
\tilde{\operatorname{Pr}}\left(\mathbf{q}_{i} \mid \mathbf{X}_{i}\right)=\frac{1}{S} \sum_{s=1}^{S} \operatorname{Pr}\left(\mathbf{q}_{i} \mid \mathbf{X}_{i}, \tilde{\eta}_{i, s}, \tilde{\nu}_{i, s}\right)
$$

where $\tilde{\nu}_{i, s}$ is a draw $s$ (out of $S$ draws) from the $N\left(0, \sigma_{\nu}^{2}\right)$ and $\tilde{\eta}_{i, s}$ from the $N\left(0, \sigma_{\eta}^{2}\right)$.

We can estimate the parameters $\theta$ by maximum simulated likelihood (MSL):

$$
\hat{\theta}_{M S L}=\arg \max _{\theta} \frac{1}{N} \sum_{i=1}^{N} \log \tilde{\operatorname{Pr}}\left(\mathbf{q}_{i} \mid \mathbf{X}_{i}\right)
$$


The MSL is consistent and asymptotically efficient for $N \rightarrow \infty$ and $S \rightarrow \infty$ (Hajivassiliou and Ruud, 1994). For fixed $S$, it is biased but the bias is generally small with a large $S$ (the bias is due to taking a log and then expectations in the ML criteria). In estimation, we use $S=50$ and the Broyden-Fletcher-Goldfarb-Shanno (BFGS) algorithm to find the optimum. We compute standard errors using a numerical estimate of the outer-product of the gradient of the MSL likelihood.

Upon estimation, it is possible to recover an unbiased predictor of the individual effects as $\hat{\eta}_{i}=E\left(\eta_{i} \mid \mathbf{q}_{i}, \mathbf{X}_{i}\right)$ and $\hat{\nu}_{i}=E\left(\nu_{i} \mid \mathbf{q}_{i}, \mathbf{X}_{i}\right)$. To do this, we can use Bayes Rule and compute using draws from the distribution of $\eta_{i}$ and $\nu_{i}$ by computing

$$
\hat{\eta}_{i}=\frac{1}{S} \sum_{s=1}^{S} \tilde{\eta}_{i, s} \frac{\operatorname{Pr}\left(\mathbf{q}_{i} \mid \mathbf{X}_{i}, \tilde{\eta}_{i, s}, \tilde{\nu}_{i, s}\right)}{\tilde{\operatorname{Pr}}\left(\mathbf{q}_{i} \mid \mathbf{X}_{i}\right)}
$$

and similarly for $\nu_{i}$ (with the same draws)

$$
\hat{\nu}_{i}=\frac{1}{S} \sum_{s=1}^{S} \tilde{\nu}_{i, s} \frac{\operatorname{Pr}\left(\mathbf{q}_{i} \mid \mathbf{X}_{i}, \tilde{\eta}_{i, s}, \tilde{\nu}_{i, s}\right)}{\tilde{\operatorname{Pr}}\left(\mathbf{q}_{i} \mid \mathbf{X}_{i}\right)}
$$


C Questionnaire 


\section{Long-Term Care Insurance Survey (Paper Version of Questionnaire for Internet Survey)}

\section{Introduction}

For purposes of this survey, when we use the term 'long-term care,' we are referring to assistance with personal care needs such as dressing, bathing, getting in and out of bed, using the bathroom or eating. A long-term care home or assisted living facility refers to a facility that offers board, meals and other basic care services for persons who need long-term care. The facility also offers medical services. It is therefore distinct from a retirement home, where no or limited care is offered.

\section{Section 1: Long-Term Care Insurance}

Q1 This survey is going to ask you questions about long-term care insurance. Which of the following best describes your current knowledge about this type of insurance?

1 A lot

2 A little

3 None at all

Q2 For purposes of this survey, we define long-term care insurance as a type of insurance that helps to pay for extended stays in a long-term care home or assisted living facility, or for personal or medical care in your home. It is typically separate from your health insurance and requires paying separate premiums. Do you have a long-term care insurance policy?

1 Yes

2 No

3 Don't Know

IF Q2==3 (Don't know) GOTO Q6

ELSE IF Q2==2(No)

Q3a Why don't you have a long-term care insurance policy? Choose the main reason.

1 I have never thought about buying one, and I have never been offered one (for instance by a financial advisor).

2 I have thought about buying one, but I have not (yet) made a decision.

3 I used to have such a policy, but I let it lapse.

4 Such insurance policies are too expensive for me.

5 Such insurance policies do not cover my needs.

6 I do not think I will need such a policy.

7 I don't know what that is.

8 Other, open...

GOTO Q6

ELSE IF Q2==1 (Yes)

Q3b How did you come to purchase that insurance policy?

1 I was offered a long-term care policy

2 I searched myself for a long-term care policy

3 Other, open ...

Q4 What is the monthly premium on that policy, including taxes?

Numeric

9999 Don't know 
IF Q4= $=9999$

Q4a Is it more than \$2001 Yes 2 No 8888888 Refuse to answer IF $\mathrm{Q} 4 \mathrm{a}==1$

Q4b Is it less than $\$ 4001$ Yes 2 No 8888888 Refuse to answer ELSE IF Q4a==2

Q4c Is it more than $\$ 1001$ Yes 2 No 8888888 Refuse to answer END IF

END IF

Q5 What is the amount of the benefit the insurance would pay out (monthly)?

Numeric

9999 Don't know

IF Q5==9999

Q5a Is it more than $\$ 2,5001$ Yes 2 No 8888888 Refuse to answer IF $\mathrm{Q} 5 \mathrm{a}==1$

Q5b Is it less than $\$ 3,5001$ Yes 2 No 8888888 Refuse to answer

ELSE IF Q5a==2

Q5c Is it more than $\$ 1,5001$ Yes 2 No 8888888 Refuse to answer

END IF

\section{END IF}

END IF

Q6 Do you have life insurance for which you currently pay a premium (or that is in force)?

1 Yes

2 No

3 Don't Know

\section{Section 2: Background}

Q7 At the present time, do you smoke cigarettes daily, occasionally or not at all?

1 Daily

2 Occasionally

3 Not at all

IF Q7==1 GOTO Q8

ELSE IF Q7==2,3

Q7a Have you ever smoked cigarettes daily?

1 Yes

2 No

IF Q7a==1 GOTO Q8

ELSE IF Q7a==2

Q7b Have you smoked 100 cigarettes or more in your life?

1 Yes

2 No

IF $\mathrm{Q} 7 \mathrm{~b}==1$ GOTO Q8

ELSE IF Q7b==2

Q7c Have you ever smoked a whole cigarette?

1 Yes

2 No 


\section{END IF \\ END IF \\ END IF}

Q8 What is the highest degree, certificate or diploma you have obtained?

1 Less than high school diploma or its equivalent

2 High school diploma or a high school equivalency certificate

3 Trade certificate or diploma

4 College, CEGEP or other non-university certificate or diploma (other than trades certificates or diplomas)

5 University certificate or diploma below the bachelor's level

6 Bachelor's degree (e.g. B.A., B.Sc., LL.B.)

7 University certificate, diploma, degree above the bachelor's level

Q9 What is your marital status?

1 married

2 living common-law

3 widowed

4 separated

5 divorced

6 single, never married

Q10 Do you have children?

1 Yes

2 No

IF $\mathrm{Q} 10==1$

Q10a How many children do you have?

Numeric $(>0)$

END IF

Q11 For 2016, what is your best estimate of the total income received by all members of your household, from all sources, before taxes and deductions?

Numeric

9999999 Don't know or prefer not to say

IF Q11==9999999

Q11a Is it more than $\$ 60,0001$ Yes 2 No 8888888 Refuse to answer

IF Q11a==1

Q11b Is it less than $\$ 120,0001$ Yes 2 No 8888888 Refuse to answer

ELSE IF Q11a==2

Q11c Is it more than \$30,000 1 Yes 2 No 8888888 Refuse to answer

\section{END IF}

END IF

Q12 Do you consider yourself retired?

$1 \mathrm{Yes}$

2 No

IF $\mathrm{Q} 12==2$ 
Q12a What is your best estimate of what total income received by all members of your household will be once you are fully retired, as a fraction of your current income?

Numeric (0\%-200\%)

9999999 Don't know

IF Q12a==9999999

Q12b Is it more than 50\%? 1 Yes 2 No 8888888 Refuse to answer

IF $\mathrm{Q} 12 \mathrm{~b}==1$

Q12c Is it less than 75\%? Yes 2 No 8888888 Refuse to answer

ELSE IF Q12b==2

Q12d Is it more than 25\%? 1 Yes 2 No 8888888 Refuse to answer

\section{END IF}

END IF

END IF

Q13 Do you own your primary residence?

1 Yes

2 No

IF $\mathrm{Q} 13==1$

Q13a What is the current market value of your residence?

Numeric

9999999 Don't know

IF Q13a==9999999

Q13b Is it more than $\$ 300,000$ ? 1 Yes 2 No 8888888 Refuse to answer

IF $\mathrm{Q} 13 \mathrm{~b}==1$

Q13c Is it less than $\$ 600,000$ ? 1 Yes 2 No 8888888 Refuse to answer ELSE IF Q13a==2

Q13d Is it more than $\$ 150,000$ ? 1 Yes 2 No 8888888 Refuse to answer

\section{END IF}

\section{END IF}

Q14 How much do you still carry as a mortgage, as a proportion of the current market value of your residence?

1 Less than $20 \%$

2 Between 20 and $40 \%$

3 Between 40 and $60 \%$

4 More than $60 \%$

5 Don't know

END IF

Q15 - We are interested in your pension plan and its nature, if you have one. Do you currently contribute to, or receive benefits from, an employer provided pension plan?

1 Yes

2 No

3 Don't Know

IF Q15==1

Q15a Is your pension plan a defined-benefit or a defined-contribution plan? A defined-benefit plan is one where you receive fixed income in retirement for as long as you live and you don't 
get to decide how much is contributed and how it is invested. A defined contribution plan is one where you decide how the contributions are invested and you receive at retirement the amount accumulated from your contributions.

1 Defined-benefit

2 Defined-contribution

3 Other

4 Don't Know

END IF

Q16 What is your best estimate of how much you have accumulated in Registered Retirement Savings Plans (RRSPs), Tax-Free Savings Accounts (TFSAs) and other savings accounts?

Numeric

9999999 Don't know or prefer not to say

IF Q16==9999999

Q16a Is it more than $\$ 50,000$ ? 1 Yes 2 No 8888888 Refuse to answer

IF $\mathrm{Q} 16 \mathrm{a}==1$

Q16b Is it less than $\$ 200,000$ ? 1 Yes 2 No 8888888 Refuse to answer

ELSE IF Q16a==2

Q16c Is it more than $\$ 10,000$ ? 1 Yes 2 No 8888888 Refuse to answer

END IF

END IF

Q17 Looking at the following list of health conditions, has a doctor ever told you you had:

[Check any of:]

1 Heart disease

2 Stroke

3 Lung disease

4 Diabetes

5 Hypertension

6 Depression or other mental health problems

7 Cancer

\section{Section 3: Risk Perception}

Q18 On a scale of 0 to 100 , where 0 is absolutely no chance and 100 is absolutely certain, what do you believe is the percent chance you will live to age 85 or more?

Numeric (0-100)

9999999 Don't know

Q19 On a scale of 0 to 100, where 0 is absolutely no chance and 100 is absolutely certain, what do you believe is the percent chance you will live more than 1 year during your lifetime with two or more limitations in activities of daily living? Activities of daily living include eating, bathing, getting dressed, walking about one's home and getting in and out of bed.

Numeric (0-100)

9999999 Don't know

IF Q19>0

Q19a 2 or more years?

Numeric (Range 0 - Answer to Q19) 
9999999 Don’t know

IF Q19a $>0$

Q19b 4 or more years?

Numeric (Range 0 - Answer to Q19a)

9999999 Don't know

\section{END IF}

END IF

Q20 Of course nobody wishes to go to a long-term care home, but sometimes this becomes necessary. On a scale of 0 to 100 , what do you believe is the percent chance that you will have to move to a longterm care home because of important limitations in your activities of daily living?

Numeric (0-100)

9999999 Don't know

Q21 On a scale of 0 to 100 , what do you believe is the percent chance that your family would take up the responsibility of taking care of you if you had important limitations in activities of daily living? Numeric (0-100) 9999999 Don't know

Formal care refers to that provided by qualified caregivers who are usually paid and unrelated to the person receiving care; informal care refers to that usually provided for free by relatives. Please keep these definitions in mind for the following questions.

Q22 Formal care refers to that provided by qualified caregivers who are usually paid and unrelated to the person receiving care; informal care refers to that usually provided for free by relatives.

Do you agree with the following statements? (Answers: 1 Strongly Agree; 2 Agree; 3 Disagree; 4 Strongly Disagree; 5 Don't know)

Q22a It is the responsibility of the family, when feasible, to take care of elderly parents

Q22b Parents should set aside money to leave to their children or heirs once they die, even when it means somewhat sacrificing their own comfort in retirement

Q22c It is children's duty to provide their parents with informal long-term care or to pay for their formal long-term care, should the need arise.

Q23 Formal care refers to that provided by qualified caregivers who are usually paid and unrelated to the person receiving care; informal care refers to that usually provided for free by relatives.

If you found yourself in a situation where you needed long-term care, which type of care would you prefer to receive: formal or informal?

1 Formal

2 Informal

3 Don't know

\section{Section 4: Literacy and Knowledge}

Now we would like to ask some questions about your familiarity and comfort with financial concepts. Please answer these questions the best you can. 
Q24 Suppose you have $\$ 100$ in a savings account, the interest rate is $2 \%$ per year and you never withdraw money. After 5 years, how much will you have in this account in total?

1 More than $\$ 110$

2 Exactly $\$ 110$

3 Less than $\$ 110$

4 Don't know

Q25 True or false? You should invest most of your money in a single stock that you select rather than in lots of stocks or in mutual funds.

1 True

2 False

3 Don't know

Q26 Suppose the chances of someone aged 50 living to age 85 are $60 \%$. What do you think the chances are that this same person will live to age 60 ?

1 Fewer than $60 \%$

2 More than $60 \%$

3 Don't know

Q27 Which of the following statements comes closest to describing the amount of financial risk that you are willing to take when you save or make investments?

1 I am willing to take substantial financial risks expecting to earn substantial returns

2 I am willing to take above average financial risks expecting to earn above average returns

3 I am willing to take average financial risks expecting to earn average returns

4 I am willing to take under average financial risks expecting to earn under average returns

$\mathrm{IF} \mathrm{PROV}=\mathrm{QC}$

Q28 In 2016, what is the average monthly cost of staying in a private, unsubsidized long-term care home (CHSLD) if you are uninsured (for a private room)? This would include the cost of room and board as well as that of all personal and nursing care.

Numeric

9999999 Don't know

IF Q27==9999999

Q27a Is it more than $\$ 3,000$ ? 1 Yes 2 No 8888888 Refuse to answer

IF Q27a==1

Q27b Is it less than \$5,000? 1 Yes 2 No 8888888 Refuse to answer

ELSE IF Q27a==2

Q27c Is it more than $\$ 1,000$ ? 1 Yes 2 No 8888888 Refuse to answer

END IF

END IF

END IF

TEXT

IF PROV $=$ QC: $\$ H O M E=$ subsidized long-term care homes (CHSLD)

IF $\mathrm{PROV}=\mathrm{ON}$ : $\$ \mathrm{HOME}=$ long-term care homes

Q29 Are [\$HOME] free to the user?

1 Yes 
2 No

IF Q29==2

Q29a In 2016, what is the monthly fee that you think you would have to pay in [\$HOME] for a private room?

Numeric

9999999 Don't know

Q29b Is there a reduced user contribution if you have low personal resources (income and assets)?

1 Yes

2 No

Q29c If you receive benefits from a long-term care insurance, how does that affect the user contribution you have to pay in [\$HOME] if you have low personal resources?

1 It increases my fee

2 It decreases my fee

3 It does not affect my fee

4 Don't know

END IF

Q30 Is there a waiting period to obtain a room in a [\$HOME]?

1 Yes

$2 \mathrm{No}$

IF $\mathrm{Q} 30==1$

Q30a On average, how many months do you think the wait is in your province?

Numeric $(>0)$

9999 Don't know

END IF

Q31 If you purchase a long-term care insurance policy and you stop paying premiums after having paid them for several years, do you generally get reimbursed for what you already paid?

1 Yes

2 No

3 Don't know

\section{Section 5: Preferences for Insurance Products}

We are going to show you some simple insurance policies and ask you to rate those. You can assume that if you were to have two or more limitations in activities of daily living, the insurance company offering you this product would pay the benefits no matter what the circumstances. Once you receive benefits, you do not pay any premiums.

Each product has three attributes:

a) a monthly premium you have to pay;

b) a monthly benefit if you have 2 or more limitations in activities of daily living, starting 3 months after your limitations have been verified; and

c) a payout to your survivors if you die before age 85 . 
Assume that if you are healthy and you stop paying premiums for 3 consecutive months, the contract is cancelled and you lose coverage.

The premium cannot increase once you have purchased the product. Finally, the benefits are adjusted for inflation (indexed).

$* * * * *$

Randomization scheme

Parameters:

$$
\begin{gathered}
\text { Benefit_ltc }=[2000,3000,4000] \text { with probability }[0.33,0.33,0.33] \\
\text { Benefit_life }=[0,10000,25000] \text { with probability }[0.6,0.2,0.2]
\end{gathered}
$$

With these benefits we will provide EPremium ( $3 \times 3=9$ data points; see table attached) which is the fair premium by age and sex.

The premium for the contract is given by (please round to nearest dollar):

prem $=$ EPremium $*$ Load where Load $[0,6,0.8,1.0,1.2,1.4]$ with probability $[0.2,0.2,0.2,0.2,0.2]$

Randomize both Benefits and Load independently ( $9 \times 5$ possibilities) for 5 plans (each respondent gets 5 draws of Benefit_ltc, Benefit_life and Load).

Present each plan following...

Example:

[Scenario]

\begin{tabular}{|l|l|l|}
\hline While healthy... & $\begin{array}{l}\text { Once you have at least } 2 \\
\text { limitations in your activities of } \\
\text { daily living... }\end{array}$ & When you pass away... \\
\hline You pay \$[prem] per month & $\begin{array}{l}\text { You receive \$[benefit_ltc] per } \\
\text { month }\end{array}$ & $\begin{array}{l}\text { Your survivors will receive } \\
\text { \$[benefit_life] once }\end{array}$ \\
\hline
\end{tabular}

$* * * * *$

Q32-36

[Scenario]

What are the chances, $0 \%$ meaning no chance and $100 \%$ for sure, that you would purchase the policy if it were offered to you by a trusted insurance company?

Numeric (0-100) 